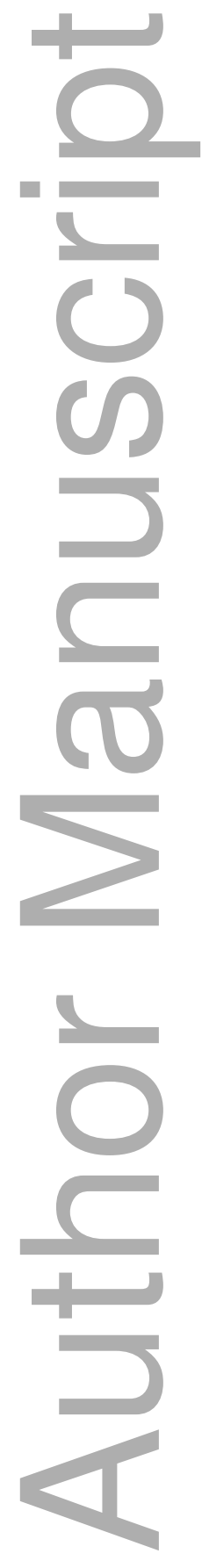

This is the author manuscript accepted for publication and has undergone full peer review but has not been through the copyediting, typesetting, pagination and proofreading process, which may lead to differences between this version and the Version of Record. Please cite this article as doi: $\underline{10.1111 / p o m s .12877}$

This article is protected by copyright. All rights reserved 


\title{
Conditional Promotions and Consumer Overspending
}

\author{
Corresponding author

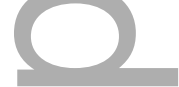 \\ Thunyarat (Bam) Amornpetchkul \\ Graduate School of Business Administration, National Institute of Development Administration \\ 118 Seri-Thai Road, Bangkapi, Bangkok 10240 Thailand \\ Phone: (+66) 2727-3997 \\ Fax: (+66) 2374-3282 \\ E-mail: thunyarat.a@nida.ac.th
}

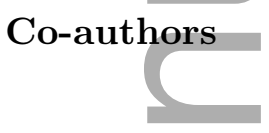

Hyun-Soo Ahn

Stephen M. Ross School of Business, University of Michigan

701 Tappan St. Ann Arbor, MI 48109-1234 USA

Phone: (734) 764-6862

Fax: (734) 764-2555

E-mail: hsahn@umich.edu

Özge Şahin

The Johns Hopkins Carey Business School

100 International Drive, Baltimore, MD 21202 USA

Phone: (410) 234-9417

Fax: (410) 234-9439

E-mail: ozge.sahin@jhu.edu 


\title{
Conditional Promotions and Consumer Overspending
}

\author{
Thunyarat (Bam) Amornpetchkul \\ Graduate School of Business Administration, National Institute of Development Administration, Bangkok, Thailand, \\ thunyarat.a@nida.ac.th

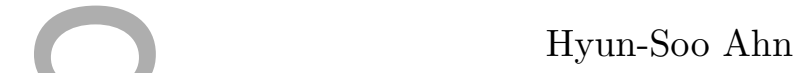 \\ Stephen M. Ross School of Business, University of Michigan, Ann Arbor, USA, hsahn@umich.edu \\ $\square$ \\ Özge Şahin \\ Carey Business School, Johns Hopkins University, Baltimore, USA, ozge.sahin@jhu.edu
}

This paper investigates the effects of conditional promotions (e.g., buy 2 or more, get 30\% off; spend $\$ 50$ or more, get $\$ 15$ off) on consumer behavior and the seller's profit. When a deal is presented with a minimum purchase quantity or a minimum spending requirement, experimental studies have shown some consumers are induced to spend more in order to obtain a discount. To study this behavior, we model a market in which consumers can be heterogeneous in two dimensions: willingness to pay for the product and deal proneness to a price discount. We examine two types of conditional promotions that are widely used in practice: i) all-unit discount, in which a price reduction applies to every unit of a purchase once the minimum requirement is met, and ii) fixed-amount discount, in which a fixed amount of discount is awarded to the total expense that meets the requirement. We show that deal-prone consumers may be induced to overspend when offered a conditional discount. However, consumer overspending benefits the seller only when the market contains a sufficiently large proportion of highly deal-prone or high-valuation consumers. Comparing the two types of discounts, we show that the all-unit discount outperforms the fixed-amount discount when the regular price for the product is high, whereas the fixed-amount discount is more profitable than the all-unit discount when some consumers would make a purchase even without a discount. Our study suggests adopting an appropriate type of conditional discount can effectively improve the seller's profit over what would be obtained through selling at the regular price or a conventional price markdown. Furthermore, we find that conditional discounts can also improve consumer welfare, resulting in win-win situations for both retailers and consumers.

Key words: price promotions, retail pricing, conditional promotions, overspending, deal-prone consumers History: Received: August 2015; accepted: March 2018 by William Cooper after two revisions.
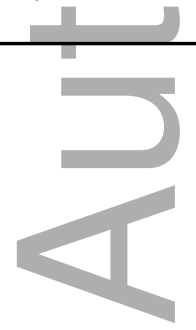


\section{Introduction}

Price promotion is a key component in today's retailing. In 2010, the total promotion spending in the United States reached $\$ 337$ billion, of which $85 \%$ was spent on price discounts (Borrell Associates 2010). Retailers employ price promotions to increase revenues and accelerate the disposal of excess inventory (Blattberg et al. 1981). Common forms of price promotions include price markdowns (e.g., $20 \%$ off the regular price), bundling (e.g., buy shirt and pants together and save $\$ 20$ ), and conditional discounts (e.g., buy 2 or more and get $20 \%$ off).

Conditional discounts are increasingly more popular in practice. In 2010, they accounted for $26 \%$ of total coupon distribution, and as much as $33 \%$ among grocery products. In consumer packaged goods, the use of conditional discounts increased by $10.3 \%$ between 2009 and 2010 (NCH Marketing Services 2011). Retailers typically offer conditional discounts in the form of either percent off or dollars off. Some examples include Easy Spirit offering 20\% off a purchase of two or more pairs of its shoes, and Dressbarn offering $\$ 10$ off a purchase of two or more of its dresses. A distinct feature of conditional discounts is that the deal is always coupled with an eligibility requirement, mostly in the form of a minimum purchase quantity or a minimum spending amount, that customers must meet or exceed to receive the discount. This strategy can benefit retailers in several ways: it allows finer price discrimination contingent on purchase quantity or spending, and potentially induces buyers with higher consumption levels or reservation prices to consume more than what they would without a discount offer.

Most existing literature on price promotions identifies price elasticity as the main driver behind buyers increasing their purchase quantity in response to a price reduction (Jeuland and Narasimhan 1985, Bell et al. 1999). However, this argument falls short of explaining why some consumers go the extra mile and buy a significantly larger quantity than what they actually need just to qualify for the deals. In fact, stories about impulsive, deal-driven shopping behavior regularly appear in news articles, popular press magazines, and personal blogs (Klaft Sep. 3, 2011, Tuttle Jul. 23, 2010, Sherman Feb. 5, 2009, Fontinelle Aug. 17, 2011, Tsai 2007).

Such shopping behavior is referred to in the literature as "deal proneness," which is the propensity to purchase products when they are offered on a "deal" basis (Hackleman and Duker 1980). Existing studies on this subject explain that deal proneness arises as consumers gain psychological benefits from paying a lower-than-expected price for a product (Schindler 1998, Laroche et al. 2001, DelVecchio 2005). This enhanced positive feeling associated with the transaction is referred

to as "transaction utility" (Thaler 1985). Consumers who receive transaction utility when acting on a satisfactory deal are labeled "deal-prone." Consumers who are not sensitive to such cognitive benefits and value a discount offer based solely on its monetary value are called "value-conscious" (Lichtenstein et al. 1990). To investigate how deal proneness influences purchase decisions, we 
define overspending as a situation in which a deal-prone consumer increases her purchase quantity purely due to the transaction utility received from completing a deal.

The heterogeneity in both consumer deal proneness and consumer willingness to pay results in multiple consumer segments that make different purchase decisions when facing a discount offer. Thus, when designing a price promotion, retailers must account for the impact of the deal on different groups of consumers. This problem is challenging because how terms of promotional offers influence purchase decisions of heterogeneous consumers is not clear, nor is which discount policy should be adopted for a given set of market parameters. Our paper aims to study the effects of conditional discounts on consumer behavior and the seller's profitability. In particular, we focus on two of the most common forms of conditional discounts: (i) all-unit discount, in which the price reduction (in percentage or dollars off) applies to every unit if the eligibility condition is met, and (ii) fixed-amount discount, in which a fixed discount (e.g., $\$ 10$ off) is applied to the total expense that satisfies the condition. We note, however, that these two forms of discounts include many other discount formats observed in practice. For example, a price markdown is a special case of the all-unit discount with no minimum purchase requirement, and mixed bundling with a limit of one deal per transaction is a special case of the fixed-amount discount.

Our research questions are as follows: 1) How do different types of consumers respond to conditional discounts? How do conditional discounts induce consumers to overspend? 2) When should a retailer offer conditional discounts? and 3) What are the market conditions that favor a fixedamount discount to an all-unit discount or vice versa? To answer these questions, we consider a model of a single seller facing heterogeneous consumers whose marginal consumption surplus decreases in the quantity they consume. Consumers are heterogeneous in two dimensions: their cognitive attitude toward a deal (deal-prone or value-conscious) and valuation (how much they value consumption of the product). Facing these consumers, the seller's problem is to decide whether to offer a discount, and if so, which discount type (all-unit or fixed-amount) and what specific terms of discount to offer in order to maximize his expected profit.

To our knowledge, this paper is the first to analytically investigate consumers' heterogeneity in deal proneness and their response to conditional discounts. We show that a conditional discount can induce deal-prone consumers to overspend (spend more than a value-conscious consumer), which may increase the seller's profit. In particular, we show that a conditional discount is strictly more profitable than selling at the regular price when either consumer willingness to pay for the product is low, or deal-prone consumers are present in the market. A conditional discount also dominates a conventional price markdown when a sufficiently large proportion of consumers are deal-prone. Furthermore, we identify market conditions under which the all-unit or the fixed-amount discount is more profitable than the other. We show, however, that regardless of the type of discount used,

\section{This article is protected by copyright. All rights reserved}


inducing consumers to overspend is not always optimal. Consumer overspending benefits the seller only when the market contains a sufficient proportion of highly deal-prone consumers. Moreover, in contrast to a natural belief that offering a discount is only beneficial when consumers have low valuation, we show that the seller can in fact use a conditional discount to improve profit when some consumers are deal-prone and have high valuation of the product. Finally, we investigate the effects of conditional discounts on the consumer and social welfare and find that conditional discounts can increase consumer welfare despite their overspending. This finding suggests conditional discounts can lead to win-win situations for both the retailer and consumers, and hence can be used to improve the overall social welfare, compared to traditional price markdowns.

\section{Literature Review}

We will review three major streams of literature on sales promotion and consumer deal proneness. The first stream of work relevant to ours is on price promotions. One of the most common forms of price promotion is a simple price markdown. Early studies on this subject explained sales as a price differentiation strategy that increases the seller's profit from certain groups of buyers (e.g., informed buyers, Varian 1980; brand switchers, Bell et al. 1999). Other works analyzed the profitability of periodic price reduction policies and proposed optimization models, taking into account consumers' promotion response and retailers' inventory levels (Lazear 1986, Smith and Achabal 1998, Gupta et al. 2006). Most of these studies on price markdowns viewed a price discount as a tool to help balance sales and remaining inventory of perishable items during a finite selling horizon. Our paper, on the other hand, considers price promotions as mechanisms to help stimulate sales that can be temporarily offered at any period during the selling season. Furthermore, conventional price markdowns are not contingent on the purchase quantity, whereas the conditional discounts considered in our paper require buyers to purchase at least the specified minimum quantity. This difference in pricing schemes allows us to investigate another potential benefit of price promotions in enticing consumers to increase their purchase quantity to complete the deal, which is not observable under price markdowns. A more characteristically similar price promotion mechanism to a conditional discount is a quantity discount. A number of papers on quantity discounts analyzed a cost-minimizing or profit-maximizing problem of a supplier selling to a buyer, where price discounts are given on large order sizes (Monahan 1984, Dada and Srikanth 1987, Corbett and de Groote 2000). A small subset of papers compared different types of quantity discounts (e.g., all-unit vs. package pricing in a supply chain, Wilcox et al. 1987; all-unit vs. incremental discount in a supply chain, Weng 1995; all-unit vs. incremental discount in retailing, Amornpetchkul 2017). However, research has not addressed the comparison between all-unit and fixed-amount discounts in retailing. 
The closest price promotion mechanisms to the conditional discounts, both in terms of structure and usage, are certain forms of bundling. The bundling literature traditionally considered pure bundling, pure unbundling, and mixed bundling (Schmalensee 1984, Chuang and Sirbu 1999, Herrmann et al. 1997). Other papers broadened their scope to consider bundling schemes in which many more combinations of products are offered to consumers (Hanson and Martin 1990, Venkatesh and Mahajan 1993). However, challenges in pricing many different bundles reduce the attractiveness of bundling when selling a large number of products. On the other hand, under a conditional discount, a uniform discount rate (or discount amount) applies as long as the purchase quantity (or spending amount) meets a single minimum requirement. This structure makes implementing a conditional discount and communicating it to consumers simpler and more straightforward, which explains why conditional discounts are widely used in retailing.

The second stream of literature is on consumer response to price promotions. The framing literature compared consumer response to price promotions framed in percentage terms and in dollar terms. For example, Chen et al. (1998), Hardesty and Bearden (2003), and Gendall et al. (2006) compared the consumer perception of the value of price discounts presented in percentages and dollars. Their experimental studies show that participants perceived discounts on high-priced items framed in dollars to be more significant than the same discounts framed in percentage. These papers' focus and methodology differ from those in the present paper. They experimentally study consumer response to different presentations of the same price promotion, whereas in this paper, we analytically compare structurally different price discount policies. Another area of growing interest related to consumer response to price discounts is strategic consumer behavior. A typical setting for this subject is one in which a seller faces a dynamic pricing problem in the presence of strategic consumers who can observe varying prices of the product over multiple periods and decide whether and when to buy the product. Several studies have shown the optimal prices may increase or decrease over time, depending on the consumers' valuation of the product and their willingness to wait (Su 2007, Besbes and Lobel 2015). The findings from our paper are similar in the sense that the optimal pricing policies are characterized by the consumers' valuation of the product and their responses to price discounts (deal proneness). However, we consider a single-period setting; hence, strategic consumer behavior does not apply. Other papers in this stream study the effects of promotions that require a minimum spending amount or multiple-unit purchases on consumer purchase behavior. Using results from experiments, Wansink et al. (1998) show that multipleunit prices result in an increase in sales over a single-unit price, and Lee and Ariely (2006) show that conditional discounts are effective in influencing consumers' spending, especially when their shopping goals are less concrete. Foubert and Gijsbrechts (2007) study bundle promotions and find that this type of promotion is far more effective at inducing consumer switching behavior than

\section{This article is protected by copyright. All rights reserved}


at boosting category sales. Although these papers show that conditional discounts can influence consumer behavior, they do not compare the two types of conditional discounts considered in the current paper, and do not study the seller's profit-maximizing promotional strategies.

Finally, the third stream of relevant literature is on consumer deal proneness. Researchers have extensively studied the existence and characteristics of deal-prone consumers over the past few decades (Hackleman and Duker 1980, Schindler 1998, DelVecchio 2005, Kukar-Kinney et al. 2012). A number of papers explain an increase in demand when a deal is offered, using reference price effects under which the consumer's propensity to buy increases as the current price becomes significantly lower than the reference price (Krishnamurthi et al. 1992, Greenleaf 1995, Popescu and $\mathrm{Wu} 2007)$. However, the study of how the reference price influences the purchase quantity of an individual consumer remains limited (see Mazumdar et al. (2005) for more literature review). In our paper, we examine how a good "deal" (in terms of discount from the original price) influences a consumer's decision whether to purchase or not as well as the purchase quantity. On a related subject, Thaler $(1985,1999)$, and Lichtenstein et al. (1990) employed the theory of mental accounting and reference price to explain that the consumer's propensity to purchase products when a deal is offered is driven by transaction utility. Schindler (1992) and Heath et al. (1995) provided experimental results supporting the assertion that consumers are more likely to purchase when a deal is offered if they perceive the price reduction to be sufficiently significant. These studies, however, do not analytically model consumer deal proneness when multiple units are purchased, and do not investigate how deal-prone consumers respond to different types of deals. A limited number of papers study the purchase behavior of deal-prone consumers under different promotion types. Lichtenstein et al. (1997) identify a consumer segment that is deal-prone across various types of promotions. Laroche et al. (2003) study deal-prone consumer perception and purchase intention when coupons and two-for-one promotions are offered. However, the papers in this area are mostly empirical and experimental, aiming to understand consumer behavior rather than the seller's profit, which is different from our analytical approach.

Overall, what primarily distinguishes our work from the existing literature is that we are the first to compare the profitability and the impact on consumer purchase behavior of all-unit and fixedamount discounts, two of the most commonly used price promotions in retailing. Furthermore, we analytically model consumer deal proneness and investigate its implications on consumer spending under conditional discounts.

\section{Model}

We consider a monopoly seller's pricing decisions for a product category with a single unit price $p$ (e.g., shirts of different colors or sizes, yogurt of different flavors, shampoos of different types, but all 
are sold at the same price). To reflect a retail price regulation commonly imposed by a manufacturer, we assume the retail price $p$ is exogenous to the seller, as is the case for a manufacturer's suggested retail price (MSRP) in practice. However, the seller can use a price promotion (discount) to adjust the price at which the product is sold.

Although many different forms of discounts are used in retailing, our paper focuses on conditional discounts, which refer to discounts that are applied only when a consumer satisfies the purchase condition (e.g., minimum purchase quantity, minimum spending). In particular, we examine two widely used forms of conditional discounts: all-unit discount (A) and fixed-amount discount (F). These two forms of discounts capture all types of price promotions that Lichtenstein et al. (1997) identified as the most commonly employed (e.g., buy-one-get-one-free, sales, coupons, cents-off). ${ }^{1}$ In practice, retailers may sometimes offer a conditional discount at the store level, where a consumer can purchase a basket of different items to get the discount (e.g., Kohl's coupon code for $\$ 20$ off a purchase of $\$ 100$ or more). However, our paper only focuses on the conditional discounts offered at the product category level, which are also commonly practiced by many retailers - both in the form of all-unit discounts (e.g., Disney's promotion on its plush toys: buy 2 or more for $\$ 16$ each, or buy 1 for $\$ 19.95$; Target's promotion on select brands of short-sleeve tees: buy 2 or more for $\$ 6$ each, or buy 1 for \$8) and fixed-amount discounts (e.g., Walgreens' promotion of "save $\$ 2$ on 2 or more NIVEA Men shaving gels," Whole Foods' promotion of "save $\$ 1$ on 2 or more Häagen-Dazs 1 pt ice cream).

\section{All-Unit Discount (A)}

In an all-unit discount, a discount is applied to all purchased units if a consumer's purchase meets a minimum eligibility requirement (e.g. buy 2 or more and get $25 \%$ off). To represent the terms of an all-unit discount, let $r \in[0,1)$ denote the promotion depth, or the "percent off," and let $K$ denote the minimum purchase quantity required to obtain the discount. ${ }^{2}$ For tractability purposes, we assume $K$ is a continuous parameter that provides a good approximation of the discrete quantity model without sacrificing the insights.

Let $D^{A}=(r, K)$ represent an all-unit discount. Then, the purchase price for $q$ units of the product under an all-unit discount $D^{A}$ is given by

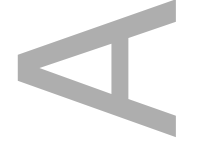

$$
P\left(q, D^{A}\right)= \begin{cases}p q & \text { if } 0 \leq q<K \\ p(1-r) q & \text { if } q \geq K\end{cases}
$$

\footnotetext{
${ }^{1}$ An incremental discount is another well-known form of conditional discounts, primarily used by suppliers or manufacturers. However, given their small presence in retailing, we do not consider incremental discounts in this paper.

${ }^{2}$ Notice that an all-unit discount with an eligibility requirement in the form of a minimum spending amount can be represented in the same way. For example, a promotion of "spend $\$ 50$ or more and get $25 \%$ off" for a product priced at $p=25$ has $K=2$ and $r=0.25$.
}

\section{This article is protected by copyright. All rights reserved}


Notice that a standard price markdown is a special case of an all-unit discount whereby $K$ is equal to the smallest sellable unit of the product.

\section{Fixed-Amount Discount (F)}

In a fixed-amount discount, the final amount a consumer has to pay is reduced by a predetermined discount amount if the consumer's purchase meets a minimum eligibility requirement (e.g., buy 2 or

more get $\$ 25$ off). To represent the terms of a fixed-amount discount, let $m \geq 0$ be the "dollars off," which is the dollar discount amount to be subtracted from the total price of an eligible purchase; let $K$ be the minimum purchase quantity to qualify for the discount. In practice, fixed-amount discounts offered with a minimum spending amount, rather than a minimum purchase quantity, are also common. Our model captures this form of fixed-amount discounts as well, because we are considering a single product category sold at a uniform price. For example, a fixed-amount discount of "Take $\$ 20$ off a purchase of $\$ 100$ or more" on a product priced at $p=25$ can be modeled with $K=4$ and $r=0.2$.

Let $D^{F}=(m, K)$ denote a fixed-amount discount. Then, the purchase price for $q$ units of the product under a fixed-amount discount $D^{F}$ is given by

$$
P\left(q, D^{F}\right)= \begin{cases}p q & \text { if } 0 \leq q<K \\ p q-m & \text { if } q \geq K .\end{cases}
$$

Notice that under a fixed-amount discount, the discount amount a customer receives for an eligible purchase does not go up with the total purchase quantity. On the other hand, under an all-unit discount, the dollar discount amount is larger for an eligible purchase of a larger quantity, because the discount is applied to all purchased units.

Next, we introduce the consumer types and discuss their corresponding utility when purchasing the product under a conditional discount.

\subsection{Consumer Types and Utility}

We assume consumers are heterogeneous in two dimensions: valuation of the product and deal proneness. A consumer may have a high ("high-type" $h$ ) or low ("low-type" $l$ ) valuation. A hightype consumer is willing to pay a higher price and consumes a larger quantity of the product, compared to a low-type consumer. We denote the proportion of high-type consumers in the market by $\gamma$. Consumers may also differ in their responses to deals. That is, some consumers may be more inclined to purchase when a deal is present. To reflect this difference, we assume there exist two types of consumers based on their cognitive behavior toward deals: value-conscious $(v)$ and deal-prone $(d)$. A value-conscious consumer only draws utility from purchasing and consuming the product (acquisition utility). On the other hand, a deal-prone consumer draws additional utility 
when purchasing the product at a sufficiently large discount (transaction utility). The proportion of deal-prone consumers in the market is denoted by $\beta$.

Notice that the two attributes of consumers - valuation and deal proneness - represent different aspects of consumer behavior. That is, a consumer's valuation is based solely on her liking of the product, whereas the consumer's deal proneness measures her cognitive response to a pricing scheme. Thus, in our model, we assume these two attributes are independent. This gives rise to four different consumer segments: high-type deal-prone $(h d)$, high-type value-conscious $(h v)$, low-type deal-prone $(l d)$, and low-type value-conscious $(l v)$, with a proportion of $\gamma \beta, \gamma(1-\beta),(1-\gamma) \beta$, and $(1-\gamma)(1-\beta)$, respectively.

A consumer's net utility from a purchase under a conditional discount is the sum of the acquisition utility and transaction utility, based on the acquisition-transaction utility theory proposed by Thaler (1985). We analytically introduce and study acquisition and transaction utility below.

\section{Acquisition Utility}

We define acquisition utility as the consumer's valuation less the purchase price. Let $V_{i}(q), i \in$ $\{h, l\}$ denote a type- $i$ consumer's valuation (willingness to pay) for $q$ units of the product. We assume a type- $i$ consumer receives utility $s_{i}$ from consuming each additional unit of the product up to $\theta_{i}$ units, above which consuming additional units will not increase the consumer's utility. This reflects the fact that after a certain quantity, the consumer gains no additional surplus from consuming more. We assume $s_{l}<s_{h}$ and $\theta_{l} \leq \theta_{h}$ to represent that a high-type consumer has a higher willingness to pay and a larger demand for the product, compared to a low-type consumer. Thus, $V_{i}(q)$ is given by the following equation and illustrated in Figure $1^{3}$ :

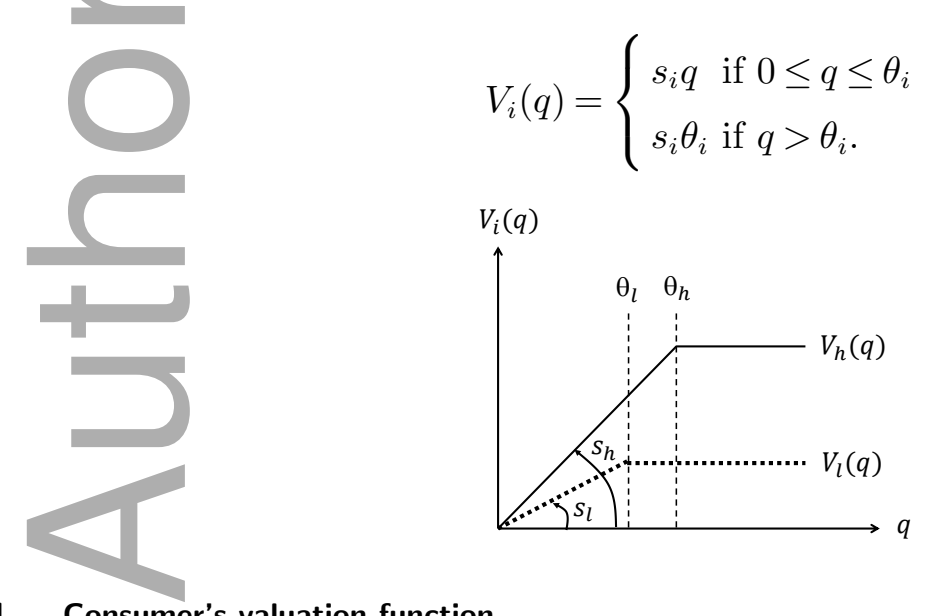

Figure 1 Consumer's valuation function

Let $P\left(q, D^{k}\right)$ denote the purchase price of $q$ units of the product under a conditional discount

\footnotetext{
${ }^{3}$ We also consider a more general model with linearly decreasing marginal valuation, which results in a concave utility
} function, in section 8.3 .

\section{This article is protected by copyright. All rights reserved}


$D^{k}, k \in\{A, F\}$. Then, a type- $i$ consumer's acquisition utility from purchasing $q$ units under a conditional discount $D^{k}$ is given by

$$
A_{i}\left(q, D^{k}\right):=V_{i}(q)-P\left(q, D^{k}\right)
$$

\section{Transaction Utility}

In addition to acquisition utility, deal-prone consumers may draw transaction utility from buying the product at a discount. Following empirical evidence that consumers judge the merits of a deal by its promotion depth (DelVecchio 2005, DelVecchio et al. 2007), we assume deal-prone consumers draw transaction utility whenever they make a purchase at what they perceive as a "good deal" (characterized by a discounted price that is significantly lower than the regular price). More specifically, for a deal-prone consumer to receive transaction utility, the promotion depth must be greater than a threshold $R$. When an all-unit discount $D^{A}=(r, K)$ is offered, we assume a deal-prone consumer will receive transaction utility of $t$ if she purchases at least $K$ to qualify for the promotion depth of $r$ which is greater than or equal to the threshold $R$. If she does not buy enough to qualify for the discount or if the promotion depth does not reach the threshold, she receives zero transaction utility. For a fixed-amount discount $D^{F}=(m, K)$, promotion depth typically refers to the amount of savings, $m$, as a percentage of the minimum spending to qualify for the discount, $p K .{ }^{4}$ Hence, we assume a deal-prone consumer facing a fixed-amount discount will receive transaction utility of $t$ if and only if she purchases $q \geq K$ to qualify for a promotion depth of $\frac{m}{p K}$ which is at least as large as the threshold $R$. Value-conscious consumers, on the other hand, do not draw transaction utility from any discount. (We later discuss a more generalized form of transaction utility in section 8.2.)

Let $T_{j}\left(q, D^{k}\right), j \in\{v, d\}, k \in\{A, F\}$ denote the transaction utility of a type- $j$ consumer ( $d$ for deal-prone and $v$ for value-conscious) when she purchases $q$ units of the product at a conditional discount $D^{k}$. Then, the transaction utility $T_{j}\left(q, D^{A}\right)$ for an all-unit discount $D^{A}=(r, K)$ is given by

$$
T_{d}\left(q, D^{A}\right)= \begin{cases}0 \text { if } q<K \text { or } r<R & T_{v}\left(q, D^{A}\right)=0 . \\ t \text { if } q \geq K \text { and } r \geq R & \end{cases}
$$

Similarly, the transaction utility $T_{j}\left(q, D^{F}\right)$ for a fixed-amount discount $D^{F}=(m, K)$ is given by equation (1) with $r$ replaced by $\frac{m}{p K}$. We sometimes refer to $t$ as "cognitive surplus" and to $R$ as "deal-prone threshold." A large value of $t$ reflects that the deal-prone consumer receives a large

\footnotetext{
${ }^{4}$ For example, a fixed-amount discount of "Take $\$ 20$ off a purchase of 2 or more" on a product priced at $\$ 50$ is equivalent to the deal "Take $\$ 20$ off a spending of $\$ 100$ or more," which is often perceived as a discount of $20 \%$.
}

\section{This article is protected by copyright. All rights reserved}


additional cognitive gain when completing a good deal. A small value of $R$ implies that the dealprone consumer can be easily induced by a discount. The value of $t$ and $R$ are product-specific, and may depend on several factors. For example, a deal-prone consumer may have a small $t$ for a lowprice-tag product (e.g., bags of chips, yogurt cups) but a larger $t$ for a high-price-tag product (e.g., shoes, shirts, hotel rooms). The deal-prone threshold $R$ may be larger for a frequently discounted item but smaller for a rarely discounted item.

Based on the definition of acquisition utility and transaction utility given above, the net utility of a type- $i j$ consumer, $i \in\{l, h\}, j \in\{v, d\}$, who purchases $q$ units of the product at a conditional discount $D^{k}, k \in\{A, F\}$, is as follows:

$$
\begin{aligned}
& U_{i v}\left(q, D^{k}\right)=A_{i}\left(q, D^{k}\right) \\
& U_{i d}\left(q, D^{k}\right)=A_{i}\left(q, D^{k}\right)+T_{d}\left(q, D^{k}\right) .
\end{aligned}
$$

In the next section, we will analyze how different types of consumers respond to deals in the form of all-unit and fixed-amount discounts. In particular, we are interested in comparing the effectiveness of these two types of discounts in boosting the consumer's purchase quantity.

\section{Consumer's Problem}

We first examine how each type of consumer behaves when a conditional discount is offered. More specifically, we will characterize how the valuation and deal proneness of a given consumer influence her purchase decision of whether to buy the product, and if so, how many units.

When facing a conditional discount $D^{k}, k \in\{A, F\}$, the consumer's utility from purchasing a quantity $q$ is given by $U_{i j}\left(q, D^{k}\right)$, as in equation $(2) .{ }^{5}$ Notice that acquisition utility $A_{i}\left(q, D^{k}\right)$ depends on the consumer's valuation type $i \in\{l, h\}$, and transaction utility $T_{j}\left(q, D^{k}\right)$ depends on the consumer's deal proneness $j \in\{v, d\}$. Both acquisition and transaction utility also depend on the discount type $k \in\{A, F\}$. Below, we discuss the consumer's problem of choosing an optimal purchase quantity under an all-unit discount and a fixed-amount discount.

\subsection{All-Unit Discount}

In an all-unit discount $D^{A}=(r, K)$, the utility that a type-ij consumer draws when purchasing $q$ units of the product is given by

\footnotetext{
${ }^{5}$ We assume if the utility from purchasing two different quantities is the same, the consumer always chooses to purchase the larger quantity due to the lower perceived per-unit price.
} 


$$
U_{i j}\left(q, D^{A}\right)= \begin{cases}s_{i} q-p q & \text { if } 0 \leq q<\min \left\{\theta_{i}, K\right\} \\ s_{i} \theta_{i}-p q & \text { if } \theta_{i} \leq q<K \\ s_{i} q-p(1-r) q+T_{j}\left(q, D^{A}\right) & \text { if } K \leq q<\theta_{i} \\ s_{i} \theta_{i}-p(1-r) q+T_{j}\left(q, D^{A}\right) & \text { if } q \geq \max \left\{\theta_{i}, K\right\}\end{cases}
$$

The first two expressions correspond to the consumer's utility when she buys fewer than the minimum requirement of $K$ units and receives no discount. Notice that when $q \geq \theta_{i}$, the consumer's valuation is $s_{i} \theta_{i}$ because units beyond $\theta_{i}$ do not increase her surplus from consumption. Analogously, the third and fourth expressions correspond to the consumer's utility when she buys at least the minimum required quantity and receives the discount.

\subsection{Fixed-Amount Discount}

In a fixed-amount discount $D^{F}=(m, K)$, the utility that a type-ij consumer draws when purchasing $q$ units of the product is given by

$$
U_{i j}\left(q, D^{F}\right)= \begin{cases}s_{i} q-p q & \text { if } 0 \leq q<\min \left\{\theta_{i}, K\right\} \\ s_{i} \theta_{i}-p q & \text { if } \theta_{i} \leq q<K \\ s_{i} q-p q+m+T_{j}\left(q, D^{F}\right) & \text { if } K \leq q<\theta_{i} \\ s_{i} \theta_{i}-p q+m+T_{j}\left(q, D^{F}\right) & \text { if } q \geq \max \left\{\theta_{i}, K\right\} .\end{cases}
$$

The difference in consumer utility between a fixed-amount discount and an all-unit discount is the discount amount. That is, the fixed-amount discount $m$ is independent of $q$ as long as $q \geq K$, but the discount amount received under the all-unit scheme, prq, increases with $q$.

The optimal purchase decision of a consumer is characterized in Proposition 1.

Proposition 1 For a given conditional discount $D^{k}, k \in\{A, F\}$, with a minimum purchase requirement of $K$, the optimal purchase decision of a type-ij consumer, $i \in\{l, h\}, j \in\{v, d\}$, is characterized by two switching curves: $\sigma_{j}\left(\theta_{i}, D^{k}\right)$ and $\bar{\theta}_{j}\left(D^{k}\right)$, as follows:

i) If $s_{i}<\sigma_{j}\left(\theta_{i}, D^{k}\right)$, no purchase is optimal.

ii) If $s_{i} \geq \sigma_{j}\left(\theta_{i}, D^{k}\right)$ and $\theta_{i}<\bar{\theta}_{j}\left(D^{k}\right)$, buying quantity $\theta_{i}<K$ at the full price is optimal.

iii) If $s_{i} \geq \sigma_{j}\left(\theta_{i}, D^{k}\right)$ and $\theta_{i} \geq \bar{\theta}_{j}\left(D^{k}\right)$, buying either $K$ or $\theta_{i}$ at the discount is optimal.

The switching curves $\sigma_{j}\left(\theta_{i}, D^{k}\right)$ and $\bar{\theta}_{j}\left(D^{k}\right)$ are increasing in $p$ and $K$, and decreasing in the depth of the discount. Furthermore, $\bar{\theta}_{d}\left(D^{k}\right) \leq \bar{\theta}_{v}\left(D^{k}\right) \leq K$ and $\sigma_{d}\left(\theta_{i}, D^{k}\right) \leq \sigma_{v}\left(\theta_{i}, D^{k}\right) \leq p$.

Proposition 1 states that the optimal purchase quantity of a type-ij consumer depends on her marginal valuation of the product $\left(s_{i}\right)$ and her maximum consumption $\left(\theta_{i}\right)$. If the consumer has very low marginal valuation compared to the price, she will not buy the product (part $\mathrm{i}$ of the 
proposition). If her marginal valuation is sufficiently high, even when her consumption level is low, she will buy the product at the full price (part ii of the proposition). When both her valuation and maximum consumption level are high, she will buy at least the required quantity $K$ and receive the discount. If the terms of a discount become more attractive (smaller $K$ or larger $r$ or $m$ ), the consumer's purchase quantity increases as the switching curves decrease.

Figures 2 and 3 together show how deal-prone consumers behave differently from value-conscious consumers for a given conditional discount $D^{k}{ }^{6}$ Because deal-prone consumers draw additional utility when they buy at a discount, they are more likely than value-conscious consumers to increase their purchase quantity to meet the requirement for the discount. Consequently, the deal-prone switching curves lie below the value-conscious switching curves, as stated in Proposition 1 and illustrated in Figure 3. This finding implies deal-prone consumers always buy no less than valueconscious consumers who have the same valuation and consumption level.

Corollary 1 Given consumer valuation $(\theta, s)$ and a conditional discount $D^{k}, k \in\{A, F\}$, with a minimum purchase requirement $K$ :

i) If $(\theta, s)$ falls between the value-conscious and deal-prone switching curves (Region $A$ and $B$ in Figure 3), a deal-prone consumer buys $K$ units, which is strictly more than what a valueconscious consumer buys.

ii) In all other cases, deal-prone and value-conscious consumers behave identically.

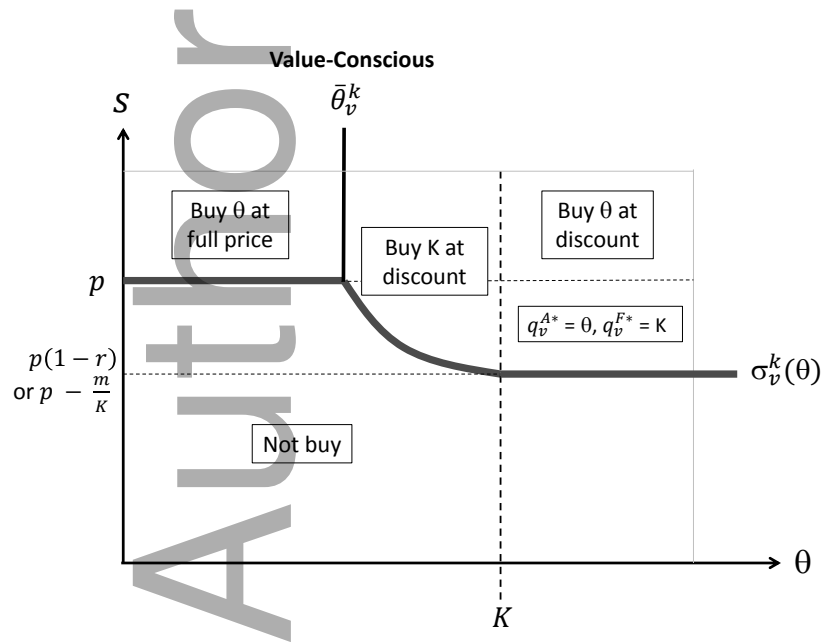

Figure 2 Value-conscious optimal purchase quantity under a conditional discount

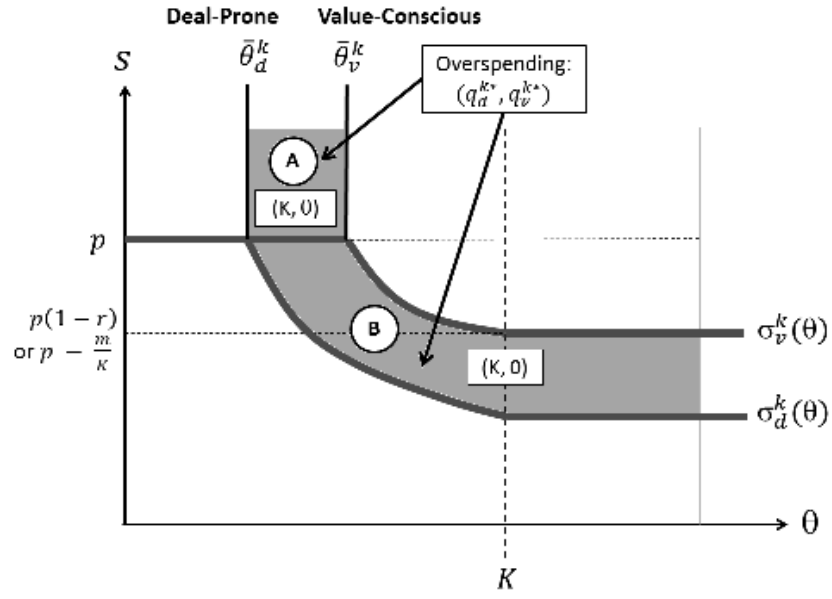

Figure 3 Cognitive overspending under a conditional discount

\footnotetext{
${ }^{6}$ For notational simplicity, we drop the valuation type $i$ and discount $D^{k}$ from the expressions displayed in the figures.
} 
Corollary 1 highlights the scenarios in which a deal-prone consumer purchases a strictly larger quantity than a value-conscious consumer, noted by Region $A$ and $B$ in Figure 3. Notice that these regions are bounded by the value-conscious and deal-prone switching curves. If the consumer valuation falls in Region $A$ (high marginal valuation, low consumption), the value-conscious consumer buys $\theta$ at no discount since her maximum consumption level is too far from the minimum requirement $K$ ( $\theta$ is below the value-conscious switching curve). On the other hand, the deal-prone consumer is willing to increase her purchase quantity to $K$ in order to qualify for the discount $(\theta$ is above the deal-prone switching curve). In this case, the deal-prone consumer ends up buying much more than what she could consume just to earn the transaction utility. If the consumer valuation falls in Region $B$ (low marginal valuation, high consumption), the value-conscious consumer does not buy the product because her valuation is too low ( $s$ is below the value-conscious switching curve). However, the deal-prone consumer still buys $K$ units to receive the discount ( $s$ is above the deal-prone switching curve). In this case, although the deal-prone consumer does not highly value the consumption of the product, she ends up making a purchase due to the transaction utility she receives from the discount.

We note that when the consumer valuation is confined by the value-conscious and deal-prone switching curves, only deal-prone consumers are enticed to purchase more in order to qualify for the conditional discount. Value-conscious consumers do not increase their purchase quantity because the acquisition utility from buying at a discount is marginally lower than that from buying at no discount (or not buying). On the other hand, deal-prone consumers are better off purchasing a larger quantity, because the transaction utility they obtain with the discount increases their overall utility. We define such a situation in which the purchase quantity of a deal-prone consumer is strictly greater than the purchase quantity of a value-conscious consumer with the same valuation as "cognitive overspending."

In the other regions outside of Region $A$ and $B$, value-conscious and deal-prone consumers behave identically. In the region above the value-conscious switching curves (to the right of Region $A$ and $B$ ), both value-conscious and deal-prone consumers purchase at the discount because their valuation falls above their respective switching curves. Likewise, in the region below the deal-prone switching curves (the the left of Region $A$ and $B$ ), both value-conscious and deal-prone consumers do not buy at the discount because their valuation falls below their switching curves.

Next, we investigate the differences between consumer behavior under the all-unit discount and the fixed-amount discount. Proposition 2 compares the switching curves and discusses the conditions under which the consumer's optimal purchase quantity is the same or different when offered the all-unit and fixed-amount discount. 
Proposition 2 Given consumer valuation $(\theta, s)$, an all-unit discount $D^{A}=(r, K)$, and a fixedamount discount $D^{F}=(m, K):{ }^{7}$

i) If $m=\operatorname{pr} K$,

ia) Both discounts result in identical switching curves: $\sigma_{j}\left(\theta, D^{A}\right)=\sigma_{j}\left(\theta, D^{F}\right)$ and $\bar{\theta}_{j}\left(D^{A}\right)=$ $\bar{\theta}_{j}\left(D^{F}\right)$, for $j \in\{v, d\}$.

ib) If $\theta>K$ and $p(1-r) \leq s<p$, the consumer purchases $\theta$ units under the all-unit discount but $K$ units under the fixed-amount discount. In all other cases, the consumer purchases the same quantity under both discount schemes.

ii) If $m<\operatorname{pr} K(m>\operatorname{pr} K)$, the switching curve under the fixed-amount discount is higher (lower) than that under the all-unit discount.

Part ia) of the proposition shows that when the same discount depth and threshold $K$ are offered, the form of discount (all-unit or fixed-amount) does not change the region in which a consumer buys at a discount. This is because the two discounts offer the same amount of savings and trigger the same transaction utility when the consumer buys the minimum purchase quantity at a discount. However, part ib) of the proposition points out that a consumer may in fact purchase different quantities under the two types of discounts. More precisely, when a consumer has a high consumption level $(\theta>K)$ but moderate willingness to pay $(p(1-r) \leq s<p)$, she buys $\theta$ under the all-unit discount, but buys a smaller quantity of $K$ under the fixed-amount discount. Under the all-unit discount, the consumer pays the discounted price for every unit. Hence, she is willing to buy as much as her maximum consumption level. On the other hand, under the fixed-amount discount, the consumer essentially has to pay the full price for any units beyond $K$. Since the full price is too high, the consumer has no incentive to purchase more than what she needs to qualify for the discount. If the amount of savings received when purchasing the minimum quantity at a discount under the two schemes are different, part ii) of the proposition states that the switching curves are also different, resulting in different purchase quantities for certain types of consumers. More precisely, the scheme offering a larger amount of savings is more attractive, as characterized by having a lower switching curve.

\section{Seller's Problem}

We now examine the seller's expected profit $\Pi\left(D^{k}\right), k \in\{A, F\}$ when a conditional discount $D^{k}$ is offered. Let $\Pi_{i j}\left(D^{k}\right)$ be the seller's expected profit from selling to a type-ij consumer. For instance, $\Pi_{h d}\left(D^{k}\right)$ represents the seller's profit from a high-type deal-prone consumer; likewise, $\Pi_{l v}\left(D^{k}\right)$

${ }^{7}$ The comparison of switching curves and consumer purchase quantities under any all-unit discount $D^{A}=\left(r, K^{A}\right)$ and fixed-amount discount $D^{F}=\left(m, K^{F}\right)$ when $K^{A} \neq K^{F}$ can also be done using the results provided in Proposition 1 and its proof. 
represents the seller's profit from a low-type value-conscious consumer. Then, the seller's total expected profit is

$$
\Pi\left(D^{k}\right)=\sum_{i \in\{l, h\}, j \in\{v, d\}} \operatorname{Pr}(i, j) \Pi_{i j}\left(D^{k}\right)
$$

To simplify our analysis, we assume in the base model that the seller's unit cost is normalized to zero (e.g., the procurement/production cost is sunk, and the seller's objective is to maximize revenues from sales.). But later in section 8.1, we will discuss how to modify our model to reflect when the unit cost is explicitly incorporated, and show that the main insights of the paper do not change.

For each type of conditional discounts, the seller's problem is to choose the terms of a discount - minimum purchase quantity $K$, and the discount rate $r$ (all-unit) or $m$ (fixed-amount) - that maximize his expected profit. The seller may also choose to offer no discount, by setting $r=0$ or $m=0$. Although offering a discount can boost the sales volume, the benefit is not costless. The seller needs to forgo the margin in exchange for the increased sales. Proposition 3 shows, however, that the presence of deal-prone consumers in the market make conditional discounts always profitable.

Proposition 3 i) If there exist deal-prone consumers $(\beta>0)$, no discount is never optimal.

ii) If all consumers are value-conscious $(\beta=0)$, no discount is optimal if and only if a) all consumers are willing to buy the product at the regular price (i.e., $s_{l} \geq p$ ) or b) only high-type consumers are willing to buy the product at the regular price and $\gamma \geq \frac{s_{l}}{p} .{ }^{8}$

Part i) of the proposition states that offering no discount can never be optimal as long as dealprone consumers are present in the market. This is because the seller can always set the terms of a discount to offer just enough discount to trigger the transaction utility of deal-prone consumers while requiring them to purchase a sufficiently large quantity for the discount to be profitable. Note that this result holds even if the regular price is set optimally. Even when all consumers are value-conscious, conditional discounts increase the seller's profit except when there exist enough consumers in the market who are willing to buy the product at the regular price (part ii)). The next result discusses which type of discounts the seller should use.

Proposition 4 i) When no consumer is willing to buy at the regular price (i.e., $s_{h}<p$ ), the all-unit discount weakly dominates the fixed-amount discount. There exists a $\bar{\beta} \in[0,1]$ such that a price markdown is an optimal all-unit discount if $\beta \leq \bar{\beta}$.

\footnotetext{
${ }^{8}$ The results in part i) and iia) continue to hold when there are $N>2$ types of consumer valuation.
}

\section{This article is protected by copyright. All rights reserved}


ii) In all other cases, the fixed-amount discount weakly dominates the all-unit discount. ${ }^{9}$

The all-unit discount outperforms the fixed-amount discount when consumer willingness to pay for the product is sufficiently low that no consumer is willing to buy at the regular price. In this case, only the all-unit discount can induce consumers to purchase a quantity strictly greater than the minimum requirement since the price reduction applies to all units purchased. The fixedamount discount can only attract consumers to buy exactly the minimum quantity required for the discount, because consumers are not willing to pay the full price for any units beyond that.

On the other hand, if some consumers in the market are already willing to buy the product at the regular price, then the fixed-amount discount is more profitable than the all-unit discount. If only the high-type consumers are willing to pay the regular price, the seller's main objective of offering a discount is to attract low-valuation consumers, who originally are not willing to pay the regular price. However, since a discount is offered to all consumers, the high-valuation consumers, who otherwise would buy up to their maximum consumption level at the full price, can also take advantage of the lowered price. Under the all-unit discount, the high-valuation consumers can "free ride" on the discount for every unit they purchase. But under the fixed-amount discount, the maximum discount the high-valuation consumers can obtain is capped at $m$. Thus, the seller's total profit is larger with the fixed-amount discount. If all consumers are willing to pay the regular price, Figure 3 shows that consumers purchase either $K$ or $\theta$ under both types of discounts. If all consumers buy $K$, then the seller can use either the all-unit or fixed-amount scheme to earn the same profit by offering the same discount of $m=\operatorname{pr} K$ to the consumers. However, if some consumers buy $\theta$, which is strictly greater than $K$ (this happens when the seller intends to offer the discount to increase the purchase quantity of the low-type only, so $\theta_{l}<K<\theta_{h}$ ), then the seller has to award them a larger amount of discount under the all-unit scheme. Hence, the fixed-amount scheme is more profitable. Note, however, that at optimality, the discount terms of the all-unit and fixed-amount scheme do not have to be the same.

Proposition 4 also shows that a price markdown is optimal when most consumers in the market are value-conscious. This is because the benefit from inducing deal-prone consumers to overspend is not significant enough to boost the seller's profit when there are not enough deal-prone consumers in the market. The seller's optimal discount schemes discussed in Proposition 3 and Proposition 4 are summarized in Figure 4a to c.

In addition to identifying the seller's optimal discount scheme, we discuss when a conditional discount is increasingly more profitable than no discount and price markdowns in Proposition 5.

\footnotetext{
${ }^{9}$ When there are $N>2$ types of consumer valuation, it continues to hold that the all-unit discount weakly dominates the fixed-amount discount when no consumer is willing to buy at the regular price, and the fixed-amount discount weakly dominates the all-unit discount when all consumers are willing to buy at the regular price.
} 


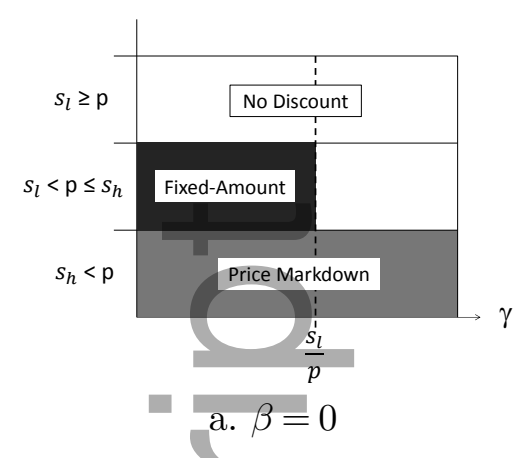

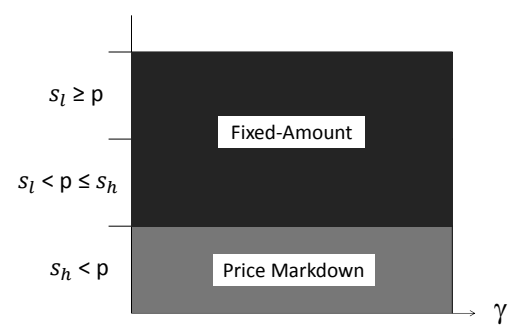

b. $0<\beta \leq \bar{\beta}$

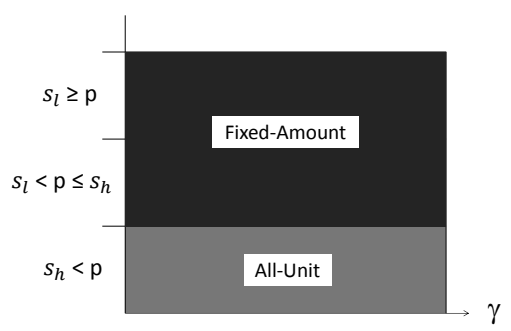

c. $\beta>\bar{\beta}$

Figure 4 Seller's optimal discount schemes

Proposition 5 The seller's profit under a conditional discount is increasingly larger than that under no discount and a price markdown as consumers become more deal-prone (either $\beta$ increases or $t$ increases).

A conditional discount is especially beneficial when the market is more deal-prone - either a larger proportion of deal-prone consumers is present, or the deal-prone consumers are more responsive to deals. Such market conditions enable the seller to induce deal-prone consumers to overspend by offering a lower discount.

So far, we have characterized the seller's optimal discount policies when selling to consumers who are heterogeneous in both valuation and deal proneness. To understand how each dimension of consumer heterogeneity affects the seller's discount policies, we analyze two special cases in which consumer valuation and deal proneness are considered in isolation.

\subsection{Deal-Prone Market with Heterogeneous Valuation}

In order to isolate the effects of the heterogeneity in consumer valuation, we consider a special case in which all consumers are deal-prone $(\beta=1)$ but are heterogeneous in valuation. That is, the market consists of two types of consumers: high-valuation deal-prone, and low-valuation dealprone. $^{10}$

When choosing the optimal discount terms, the seller needs to decide either to offer a conservative discount to increase the purchase quantity of only the high-type consumers, or to offer a more aggressive discount to increase the purchase quantity of the low-type consumers. Lemma 1 explains that offering a more generous discount (larger $r$ and/or smaller $K$ ) to generate more sales from the low-type consumers is optimal if a sufficiently large proportion of them are present in the market.

\footnotetext{
${ }^{10}$ The situation in which all consumers are value-conscious is equivalent to this special case with $t=0$.
} 
Lemma 1 For a conditional discount of type $k \in\{A, F\}$, there exists a threshold $\Gamma^{k} \in[0,1]$ such that offering a discount targeted to only high-type consumers is optimal if $\gamma>\Gamma^{k}$. Otherwise, offering a deeper discount targeted to low-type consumers is optimal.

We now examine how the threshold $\Gamma^{k}$ changes with respect to the magnitude of transaction utility, $t$. Let $\Gamma^{k}(t)$ denote the switching curve that characterizes, for a given $t$, at which $\gamma$ the seller should target the discount at which segment of consumers. An example of $\Gamma^{k}(t)$ is shown in Figure 5, where the shaded region denotes when the proportion of the high-type consumers is small $(\gamma \leq \mathrm{F}(t))$ and hence targeting the discount at the low-type segment is optimal. Notice that since all consumers are deal-prone, the seller should always offer some form of discount to increase the purchase quantity of at least one type of consumer (Proposition 3 part i). However, this does not mean that at least one type of consumer should always be induced to overspend. To induce overspending, the seller needs to offer a deep enough discount and set a sufficiently large minimum purchase quantity, which may or may not improve the overall profit. Our next result identifies when cognitive overspending is indeed optimal for the seller.

Proposition 6 When all consumers are deal-prone but heterogeneous in valuation, there exists a continuous switching curve $\Gamma^{A}(t)$ characterizing the optimal all-unit discount $D^{A *}=\left(r^{*}, K^{*}\right)$ for a given t.

i) If $\gamma>\Gamma^{A}(t)$, then $r^{*} \geq R$ and $K^{*} \geq \theta_{h}$ (only high-type consumers overspend).

ii) If $\gamma \leq \mathrm{F}^{A}(t)$, then there exists a threshold $\hat{t}$ such that $r^{*} \geq R$ and $K^{*} \geq \theta_{l}$ (at least low-type consumers overspend) for $t>\hat{t}$.

The same results hold for the optimal fixed-amount discount $D^{F *}=\left(m^{*}, K^{*}\right)$ when replacing $\Gamma^{A}(t)$ with $\Gamma^{F}(t)$, and $r^{*} \geq R$ with $m^{*} \geq p R K^{*}$.

Proposition 6 shows that it is optimal for the seller to trigger transaction utility and induce overspending when either there is a sufficiently large proportion of consumers with high valuation (large $\gamma$ ), or the magnitude of transaction utility is sufficiently large (large $t$ ). Under these conditions, the market contains enough consumers who will significantly increase their purchase quantity when offered a discount, making it profitable for the seller to induce overspending. On the other hand, when $t$ and $\gamma$ are both small, it may not be optimal to induce overspending, as illustrated by the dark colored region in Figure 5. When the transaction utility is too small and the proportion of each type of consumer is close to each other (moderate $\gamma$ ), it is not profitable for the seller to induce either type of consumer to overspend because they do not have enough mass to generate much larger sales. However, as the cognitive surplus increases, both types of consumers are willing to overspend more when their transaction utility is triggered, making overspending more profitable for the seller. Hence, the no-overspending region shrinks and finally disappears.

\section{This article is protected by copyright. All rights reserved}


The exact behavior of the switching curve with respect to $t$ is rather complicated as shown in Figures 5 and 6. (The closed-form expressions of the switching curve under each type of conditional discounts are provided in Appendix A.) For a given $\gamma$, the terms of the optimal discount are not necessarily monotone in $t$. For example, consider $\gamma=0.55$ in Figure 5 . When $t$ is small (point A), it is not optimal to induce any types of consumers to overspend $\left(r^{*}=0.4<R\right)$. As $t$ increases to a moderate leyel (point B), it becomes profitable to induce only the high-type consumers to overspend since they are willing to increase their purchase quantity far beyond their maximum consumption level $\left(K^{*}=7>\theta_{h}=4\right)$ when they receive transaction utility. When $t$ is sufficiently large (point $\mathrm{C}$ ), even the low-type consumers are willing to increase their purchase quantity by a lot $\left(K^{*}=4.65>\theta_{l}=2\right)$ due to the large transaction utility.

Notice from Figure 6 that the region where overspending is not optimal is larger under the all-unit discount than under the fixed-amount discount, both when the all-unit discount is more profitable (Figure 6a. where $p>s_{H}$ ) and when the fixed-amount discount is more profitable (Figure 6b. where $\left.p \leq s_{H}\right)$. The reason is that inducing overspending under the all-unit discount requires the seller to forgo the margin on more units of the product sold, compared to under the fixed-amount discount. Hence, overspending is less likely to be optimal under the all-unit discount.
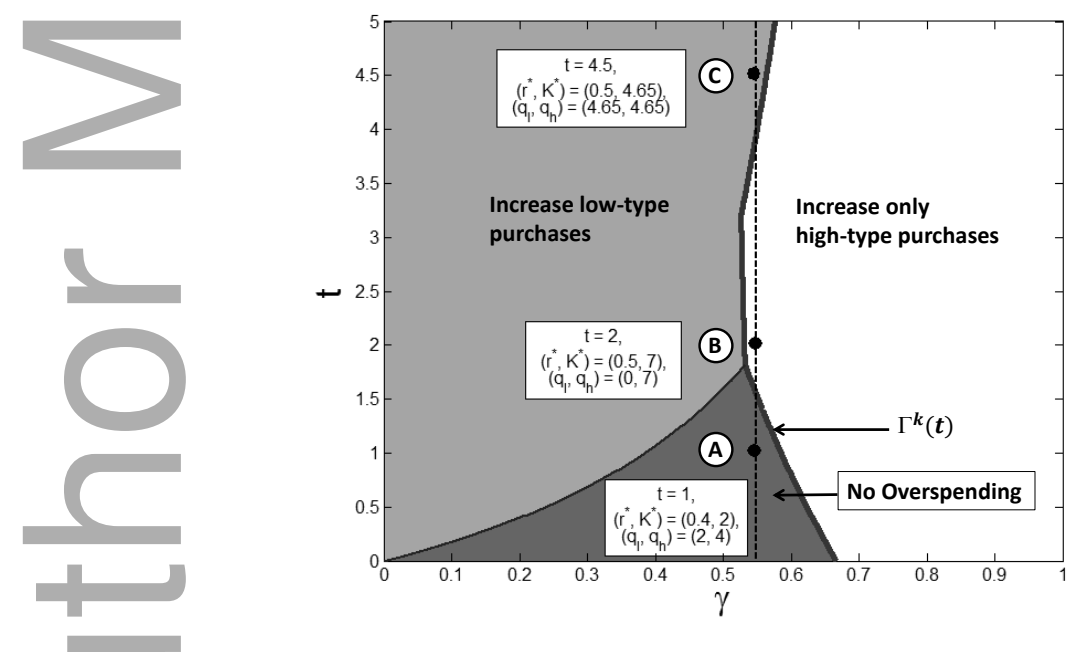

Figure 5 Switching curve $\Gamma^{A}(t): s_{l}=2.4, s_{h}=3, \theta_{l}=2, \theta_{h}=4, p=4, R=0.5$

\subsection{Homogeneous Valuation with Heterogeneous deal proneness}

To isolate the effects of the heterogeneity in consumers' attitude toward a deal, we consider a special case in which all consumers have the same valuation, characterized by the same $s$ and $\theta$, but they are either deal-prone or value-conscious.

The seller's optimal strategy is characterized in Lemma 2. 


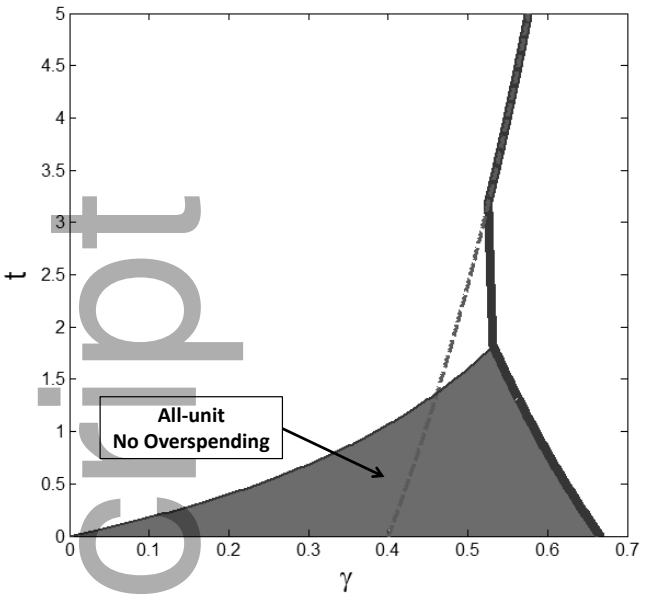

a.

Figure 6 Switching curves $\Gamma^{A}(t)$ and $\Gamma^{F}(t): s_{l}=2.4, s_{h}=3, \theta_{l}=2, \theta_{h}=4, R=0.3$. a) $p=4$, b) $p=2.8$

Lemma 2 For a conditional discount of type $k \in\{A, F\}$ :

i) There exists a threshold $\bar{\beta}^{k} \in[0,1)$ such that it is optimal to offer a discount to increase the purchase quantity of only deal-prone consumers (cognitive overspending) if $\beta>\bar{\beta}^{k}$. Otherwise, it is optimal to increase the purchase quantity of all consumers.

ii) If consumers are willing to buy at the regular price $(s \geq p)$, then $\bar{\beta}^{k}=0$. Otherwise, $\bar{\beta}^{k}=\frac{s \theta}{t+s \theta}$.

Lemma 2 part i) states that inducing overspending is optimal only when enough deal-prone consumers are present in the market. Part ii) of the lemma reveals that if the consumers are willing to buy at the regular price, then cognitive overspending is always optimal $\left(\bar{\beta}^{k}=0\right)$. In this case, since the value-conscious consumers are already willing to buy up to their maximum consumption at the full price, it is optimal to offer a discount that increases the purchase quantity of only deal-prone consumers. If the consumers are not willing to pay the regular price, the threshold $\bar{\beta}^{k}$ is given by a function that is decreasing in $t$. This implies that as deal-prone consumers receive larger transaction utility from a deep discount, the proportion of deal-prone consumers that is required for cognitive overspending to be profitable for the seller gets smaller because they are willing to overspend by a larger amount.

Next, we investigate consumer behavior and the seller's profit under the all-unit and fixed-amount discount. Interestingly, as Proposition 7 reveals, the optimal all-unit and fixed-amount discount always induce the same consumer purchase behavior and yield the same profit to the seller.

Proposition 7 When consumers have the same valuation but are different in their deal proneness, the optimal all-unit discount and fixed-amount discount always result in the same consumer purchase quantities and the same seller's profit. ${ }^{11}$

\footnotetext{
${ }^{11}$ This result continues to hold when $t$ is a uniformly distributed random variable, e.g., $t \sim U[0, \bar{t}]$.
}

\section{This article is protected by copyright. All rights reserved}


To see the intuition, notice that the only situation in which the all-unit and fixed-amount discount can structurally result in different outcomes is when a consumer buys strictly more than $K$. When all consumers share the same valuation, if the original price is small $(p \leq s)$, it will never be optimal for the seller to offer a discount at which any consumer buys more than $K$. This is because the profit from doing so is less than the profit from not offering a discount at all. If the original price is large $(p>s)$, a consumer may purchase more than $K$ if an all-unit discount $D^{A}=(r, K)$ where $p(1-r) \leq s$ is offered. However, in this case, there always exists an equivalent fixed-amount discount $D^{F}=\left(m=p r K^{F}, K^{F}=\theta\right)$, which yields the exact same outcome. Hence, at optimality, the all-unit and fixed-amount discount are equally profitable.

The results from the two special cases (sections 5.1 and 5.2) show that it is not always optimal for the seller to induce deal-prone consumers to overspend. Furthermore, we find that the all-unit and fixed-amount discount may perform differently only in the presence of heterogeneity in consumer valuation. This finding implies that the fundamental differences between the two mechanisms of conditional discounts are the different effects they have on consumers with different valuations of the product.

Next, we investigate how much profit improvement the implementation of conditional discounts can generate under different retailing scenarios. We employ a numerical study to examine this topic in the next section.

\section{Numerical Study}

We conduct two sets of numerical experiments to address a few important managerial questions regarding the use of conditional discounts in practice. More specifically, we are interested in answering the following questions: 1) By how much can a seller improve profits with a conditional discount? 2) What is the profit difference between using all-unit and fixed-amount discounts? and 3) What factors affect the magnitude of profit improvement from offering a conditional discount?

\subsection{Profit Improvement}

In the first numerical study, we compare the performance of different types of discounts under a large number of different retailing scenarios. We generate 1,296 different problem instances by varying each parameter, as summarized in Table $1 .^{12}$

\begin{tabular}{|c|c|c|c|c|c|c|c|c|}
\hline$\theta_{l}$ & $\theta_{h}$ & $s_{l}$ & $s_{h}$ & $p$ & $t$ & $R$ & $\gamma$ & $\beta$ \\
\hline 1 & $\{2,3,4\}$ & 1 & 2 & $\{0.5,1.5,2.5\}$ & $\{0.1,0.3,0.5,0.75\}$ & $\{0,0.25,0.5,0.75\}$ & $\{0.2,0.5,0.8\}$ & $\{0.2,0.5,0.8\}$ \\
\hline
\end{tabular}

Table 1 Problem parameters for the numerical study of profit improvement

\footnotetext{
${ }^{12}$ We normalize $\theta_{l}$ and $s_{l}$ to 1 , and $s_{h}$ to 2 since similar effects of changing these parameters can be observed by changing $\theta_{h}$ and $p$.
} 
For each problem instance, we solve for the optimal price markdown, all-unit, and fixed-amount discount, and compare the seller's profit under different discount schemes. Table 2 summarizes how much profit (in percentage) the seller can gain by offering an optimal price markdown, all-unit, and fixed-amount discount, over no discount. We note, however, that the instances in which the nodiscount profit is zero $(p=2.5)$ are excluded from the statistics presented in the table as the profit improvement in those cases is trivial. Since only the instances in which at least some consumers are willing to pay the regular price are considered, we observe that the profit improvement from offering the fixed-amount discount is greater than that from offering the all-unit discount, supporting the result in Proposition 4. Overall, Table 2 provides evidence to support that when using a conditional discount, the seller can expect to see a profit improvement of as much as $20 \%$ on average, which is about 10\% higher than the profit improvement obtained from a standard price markdown.

Next, we compare the performance of all-unit and fixed-amount discounts. Out of 1,296 instances, we find that the two discounts perform equally well in 688 (53.08\%) instances; the all-unit discount performs better in 297 (22.92\%) instances; and the fixed-amount discount performs better in 311 (24\%) instances. These findings reveal that about half of the time, the seller can employ either form of conditional discount to increase profits. However, the other half of the time, one discount scheme can perform better than the other, calling the seller's attention to choosing the appropriate type of conditional discount for the market he is facing. In fact, the profit differences between the two discount schemes can be significant, as reported in Table 3. (Profit improvement of the all-unit over the fixed-amount discount refers to $\frac{\text { profit from the all-unit discount - profit from the fixed-amount discount }}{\text { profit from the fixed-amount discount }}$ ) In approximately $40 \%$ of the instances in which the all-unit discount performs better than the fixedamount discount, we find that the profit improvement is at least 10\%. Likewise, an analogous analysis of the profit improvement of the fixed-amount over the all-unit discount shows a similar result, namely, that when the fixed-amount discount performs better than the all-unit discount, the profit improvement is at least $10 \%$ in about $40 \%$ of the instances.

\begin{tabular}{|c||c|c|c|c|c|}
\hline \multirow{2}{*}{ Profit Improvement when Using } & \multicolumn{5}{|c|}{ Statistics } \\
\cline { 2 - 6 } & Mean & Median & Standard Deviation & Minimum & Maximum \\
\hline Price Markdown & $10.22 \%$ & $0.00 \%$ & $25.45 \%$ & $0.00 \%$ & $98.00 \%$ \\
\hline All-Unit Discount & $19.37 \%$ & $7.48 \%$ & $27.99 \%$ & $0.00 \%$ & $175.76 \%$ \\
\hline Fixed-Amount Discount & $23.94 \%$ & $10.66 \%$ & $32.49 \%$ & $0.00 \%$ & $179.34 \%$ \\
\hline
\end{tabular}

Table 2 Statistics for the seller's profit improvement when using conditional discounts over no discount

\begin{tabular}{|c|c|c|c|c|c|c|c|}
\hline \multicolumn{7}{|c|}{ Profit Improvement of All-Unit over Fixed-Amount Discounts } \\
\hline$<-10 \%$ & $-10 \%-0 \%$ & $0 \%-10 \%$ & $10 \%-20 \%$ & $20 \%-30 \%$ & $30 \%-40 \%$ & $40 \%-50 \%$ & $>50 \%$ \\
\hline 106 & 893 & 177 & 53 & 49 & 9 & 7 & 2 \\
\hline
\end{tabular}

Table 3 Profit difference between all-unit and fixed-amount discounts

\section{This article is protected by copyright. All rights reserved}




\section{2. $\quad$ Effects of Problem Parameters}

In the second numerical study, we investigate how each parameter affects the performance of conditional discounts, compared to other discount schemes. We systematically increase the value of each parameter, one at a time, from the three base cases $\left(p>s_{h}, s_{l}<p \leq s_{h}\right.$, and $\left.p \leq s_{l}\right)$. This results in a total of 1,400 problem instances, as summarized in Table 4. In each problem, we solve for the optimal discount policies and compare the seller's profits. Table 5 presents the results.

\begin{tabular}{|c||c|c|c|c|c|c|c|c|c|}
\hline Scenario & $\theta_{l}$ & $\theta_{h}$ & $s_{l}$ & $s_{h}$ & $p$ & $t$ & $R$ & $\gamma$ & $\beta$ \\
\hline Base cases & 1 & 2 & 1 & 2 & $\{0.5,1.5,2.5\}$ & 0.2 & 0.2 & 0.2 & 0.2 \\
\hline Increase $\theta_{h}$ at steps of 0.01 & 1 & {$[2.01,3]$} & 1 & 2 & $\{0.5,1.5,2.5\}$ & 0.2 & 0.2 & 0.2 & 0.2 \\
\hline Increase $t$ at steps of 0.01 & 1 & 2 & 1 & 2 & $\{0.5,1.5,2.5\}$ & {$[0.21,1]$} & 0.2 & 0.2 & 0.2 \\
\hline Increase $R$ at steps of 0.01 & 1 & 2 & 1 & 2 & $\{0.5,1.5,2.5\}$ & 0.2 & {$[0.21,0.8]$} & 0.2 & 0.2 \\
\hline Increase $\gamma$ at steps of 0.01 & 1 & 2 & 1 & 2 & $\{0.5,1.5,2.5\}$ & 0.2 & 0.2 & {$[0.21,1]$} & 0.2 \\
\hline Increase $\beta$ at steps of 0.01 & 1 & 2 & 1 & 2 & $\{0.5,1.5,2.5\}$ & 0.2 & 0.2 & 2 & {$[0.21,1]$} \\
\hline Increase $p$ at steps of 0.01 & 1 & 2 & 1 & 2 & {$[0.51,2.5]$} & 0.2 & 0.2 & 2 & 0.2 \\
\hline
\end{tabular}

Table 4 Problem parameters for the numerical study of effects of parameters on the profit improvement

\begin{tabular}{|c||c|c|c|c|c|c|c|c|c|}
\hline \multirow{2}{*}{ Scenario } & Optimal Policy vs. Price Markdown & \multicolumn{2}{|c|}{ All-unit vs. Price Markdown } & \multicolumn{3}{|c|}{ Fixed-amount vs. Price Markdown } \\
\cline { 2 - 10 } & Mean & Median & Std. Dev. & Mean & Median & Std. Dev. & Mean & Median & Std. Dev. \\
\hline Base cases & $3.50 \%$ & $1.33 \%$ & $4.95 \%$ & $0.53 \%$ & $0.79 \%$ & $0.46 \%$ & $-2.77 \%$ & $0.80 \%$ & $15.75 \%$ \\
\hline Increase $\theta_{h}$ & $4.53 \%$ & $1.23 \%$ & $5.66 \%$ & $0.53 \%$ & $0.79 \%$ & $0.38 \%$ & $-2.72 \%$ & $0.80 \%$ & $17.14 \%$ \\
\hline Increase $t$ & $8.31 \%$ & $9.17 \%$ & $8.33 \%$ & $3.42 \%$ & $0.79 \%$ & $5.32 \%$ & $0.12 \%$ & $10.10 \%$ & $14.61 \%$ \\
\hline Increase $R$ & $3.44 \%$ & $1.33 \%$ & $3.98 \%$ & $0.46 \%$ & $0.79 \%$ & $0.38 \%$ & $-2.84 \%$ & $0.80 \%$ & $12.83 \%$ \\
\hline Increase $\gamma$ & $3.52 \%$ & $1.72 \%$ & $4.43 \%$ & $1.91 \%$ & $1.98 \%$ & $1.15 \%$ & $3.13 \%$ & $2.42 \%$ & $8.31 \%$ \\
\hline Increase $\beta$ & $8.33 \%$ & $9.17 \%$ & $6.57 \%$ & $4.75 \%$ & $1.18 \%$ & $6.03 \%$ & $0.83 \%$ & $6.15 \%$ & $14.05 \%$ \\
\hline Increase $p$ & $4.74 \%$ & $1.27 \%$ & $5.38 \%$ & $0.46 \%$ & $0.79 \%$ & $0.43 \%$ & $0.75 \%$ & $0.80 \%$ & $12.67 \%$ \\
\hline
\end{tabular}

Table 5 Statistics for the seller's profit improvement with respect to changes in problem parameters

The profit improvement of the optimal policy versus price markdown in Table 5 measure the gains in profits from using the more profitable one of the all-unit and fixed-amount discount over the price markdown. Notice that since a price markdown is a special case of an all-unit discount, the seller's profit from using the all-unit discount is always larger than that from using the price markdown. On the other hand, fixed-amount discount can be more or less profitable than price markdown. From the table, we observe that an increase in $\theta_{h}, t, \gamma$, and $\beta$ leads to larger profit improvements, whereas an increase in $R$ leads to smaller profit improvements of the optimal conditional discounts over price markdowns. This observation is consistent with the results shown in sections 5.1 and 5.2 that it is profitable for the seller to use conditional discounts to induce overspending when the market is highly deal-prone (large $t$ and $\beta$, and small $R$ ) and has high valuation (large $\theta_{h}$ and $\gamma$ ). The effects of price also follow what was shown earlier in Proposition 4. Since a larger portion of the price range considered in this numerical study falls within the region where some consumers are willing to pay the regular price $\left(p \leq s_{h}\right.$, i.e. $\left.p \in[0.51,2]\right)$, we observe that as price changes, the profit improvement of the fixed-amount discount over the price markdown is larger than in the base case. 


\section{Social and Consumer Welfare under Conditional Discounts}

One interesting question associated with any pricing or promotional tools is whether they also help improve the consumer and social welfare. This section discusses how conditional discounts can help or hurt welfare, compared to price markdowns. In our analysis, we exclude transaction utility when evaluating the consumer welfare under conditional discounts, following the arguments for an ethical evaluation in Singer et al. (1991).

Our numerical results show that, compared to price markdowns, consumer welfare and social welfare can be either larger or smaller under conditional discounts. In particular, as shown in Figure 7 , as transaction utility gets larger, consumer welfare tends to be smaller under a conditional discount than a traditional markdown. This is because consumers are more likely to be induced to overspend by a conditional discount, exceeding the quantity that maximizes their acquisition utility. While overspending gives them satisfaction from completing the deal, it could reduce their overall welfare, because consuming too much of the product does not generate additional (acquisition) utility but costs them more money. We note, however, that overspending under a conditional discount can sometimes improve consumer welfare as well, for instance, when the deal-prone consumers have a low threshold to receive transaction utility (small $R$ ) and the price is moderate $\left(s_{l}<p \leq s_{h}\right)$. In this case, it can be optimal for the seller to offer a conditional discount with a sufficient discount rate (deeper than the optimal rate for price markdown), which induces low-type consumers to overspend. Since the high-type consumers also benefit from the discount, they may actually receive a larger welfare under the conditional discount than under the price markdown, which can increase overall consumer welfare.

a.

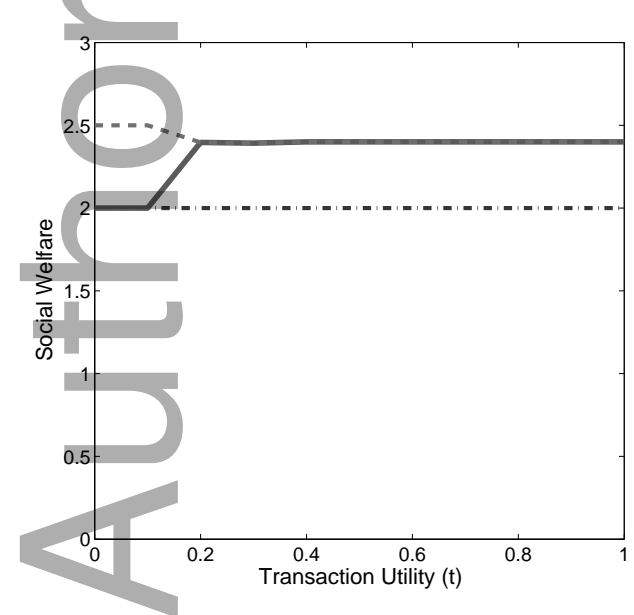

b.

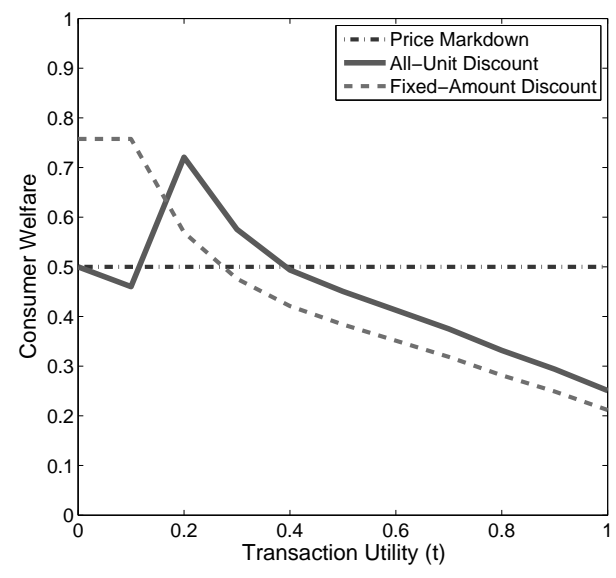

Figure 7 Social welfare and consumer welfare under conditional discounts and price markdown: $s_{l}=1, s_{h}=2, p=$ $1.5, R=0.1, \gamma=0.5, \beta=0.8$

As for social welfare, conditional discounts outperform price markdowns in most cases because an increase in the seller's profit under conditional discounts over price markdowns is generally

This article is protected by copyright. All rights reserved 
much larger. However, when the proportion of the high-type consumers is too small and when transaction utility is sufficiently large, the reduction in consumer welfare due to overspending may dominate the gain in the seller's profit, resulting in lower social welfare.

\section{Extensions}

\subsection{Positive Unit Cost}

In our base model, we assume the unit cost is normalized to zero. Here, we modify the model to reflect when the seller incurs a unit $\operatorname{cost} c$ for each unit sold, where $0<c<p$. Notice that a positive unit cost has no effect on the consumer's problem. Hence, all results regarding consumer purchase behavior (section 4) continue to hold.

For the seller's problem, the presence of a positive unit cost affects the seller's profit as follows. The seller's profit from selling $q$ units under an all-unit discount $D^{A}=(r, K)$ is given by $(p(1-$ $r)-c) q$ if $q \geq K$, and $(p-c) q$ if $q<K$. Likewise, the seller's profit from selling $q$ units under a fixed-amount discount $D^{F}=(m, K)$ is given by $(p-c) q-m$ if $q \geq K$, and $(p-c) q$ if $q<K$. Hence, with a positive unit cost, we find that the region where no discount is optimal becomes larger, and the region where cognitive overspending is optimal becomes smaller. Consequently, the following results need to be modified to reflect a positive unit cost. Proposition 3 part i), which states that no discount is not optimal as long as deal-prone consumers are present, will hold only when the unit cost is not too large. (More precisely, there exists a threshold $\bar{c}$ such that the result holds if and only if $c<\bar{c}$.) Condition b) of Proposition 3 part ii) changes from $s_{l}<p \leq s_{h}$ and $\gamma \geq \frac{s_{l}}{p}$ to $s_{l}<p \leq s_{h}$ and $\gamma \geq \frac{s_{l}-c}{p-c}$. Notice that the threshold on $\gamma$ is smaller with a positive unit cost than with no unit cost $\left(\frac{s_{l}-c}{p-c}<\frac{s_{l}}{p}\right)$, implying that the region where no discount is optimal is larger. Likewise, the results for the two special cases (sections 5.1 and 5.2) are affected in the same way such that no discount is more likely to be optimal and cognitive overspending is less likely to be optimal. All other results continue to hold in the presence of a positive unit cost.

\subsection{General Form of Transaction Utility}

To capture how deal-prone consumers may mentally respond to different levels of discount depth in a more general setting, we can generalize the transaction utility in our model to be any increasing function in the discount depth. That is, the transaction utility $T_{d}\left(q, D^{k}\right)$ when $q \geq K$ can be any increasing function in $r$ for $D^{A}=(r, K)$ and in $\frac{m}{p K}$ for $D^{F}=(m, K)$. With this modification, all results in this paper continue to hold, except only for Propositions 6 and 7 , which are specific to a closed-form of transaction utility. Note, however, that as long as there exists an upper bound of the transaction utility when the discount depth is sufficiently high (e.g., $T_{d}(r)=t$ for $r \geq R$, where $t>0$ and $R<1$; and $T_{d}(r)<t$ for $r<R$ ), then Propositions 6 and 7 will continue to hold as well. ${ }^{13}$

\footnotetext{
${ }^{13}$ The step-function transaction utility in the base model is a special case of this general form of transaction utility.
}

\section{This article is protected by copyright. All rights reserved}




\subsection{Concave Consumer Valuation}

In our base model, we assume a consumer type $i \in\{l, h\}$ has a constant marginal valuation of $s_{i}$ for the first $\theta_{i}$ units of consumption. Here, we consider an alternative model in which the marginal valuation is linearly decreasing in the units consumed, as in Chuang and Sirbu (1999). More precisely, let $v_{0}$ be the marginal valuation of the first unit of goods. Then, for a consumer type $i$, the marginal valuation of the $q^{\text {th }}$ unit of goods is given by

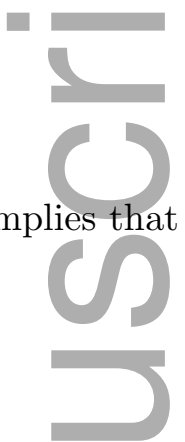

$$
v_{i}(q)= \begin{cases}v_{0}\left(1-\frac{q}{\theta_{i}}\right) & \text { if } 0 \leq q \leq \theta_{i} \\ 0 & \text { if } q>\theta_{i}\end{cases}
$$

which implies that a consumer valuation is a concave increasing function of $q$ :

$$
V_{i}(q)=\int_{0}^{q} v_{i}(x) d x= \begin{cases}v_{0} q\left(1-\frac{q}{2 \theta_{i}}\right) & \text { if } 0 \leq q \leq \theta_{i} \\ \frac{v_{0} \theta_{i}}{2} & \text { if } q>\theta_{i} .\end{cases}
$$

Solving the consumer's problem with this acquisition utility, we obtain similar results as in Proposition 1 . That is, the consumer's optimal purchase quantity under a conditional discount $D^{A}=$ $\left(r, K^{A}\right)$ and $D^{F}=\left(m, K^{F}\right)$ is characterized by two thresholds: $\underline{\theta}_{j}\left(v_{0}, D^{k}\right)$ and $\bar{\theta}_{j}\left(v_{0}, D^{k}\right), k \in\{A, F\}$, such that a type-ij consumer buys a quantity smaller than $K^{k}$ at no discount if $\theta_{i}<\underline{\theta}_{j}\left(v_{0}, D^{k}\right)$, buys exactly $K^{k}$ at discount if $\underline{\theta}_{j}\left(v_{0}, D^{k}\right) \leq \theta_{i}<\bar{\theta}_{j}\left(v_{0}, D^{k}\right)$, and buys more than $K^{k}$ at discount if $\theta_{i} \geq \bar{\theta}_{j}\left(v_{\theta}, D^{k}\right), i \in\{l, h\}, j \in\{v, d\}$. Furthermore, if $K^{A}=K^{F}$ and $m=p r K$, then $\underline{\theta}_{j}\left(v_{0}, D^{A}\right)=$ $\underline{\theta}_{j}\left(v_{0}, D^{F}\right)$ and $\bar{\theta}_{j}\left(v_{0}, D^{A}\right) \leq \bar{\theta}_{j}\left(v_{0}, D^{F}\right) .{ }^{14}$ Figures 8a and 8b graphically illustrate the consumer's optimal purchase quantity, $q_{j}\left(\theta_{i}\right)$, under the all-unit and fixed-amount discount.

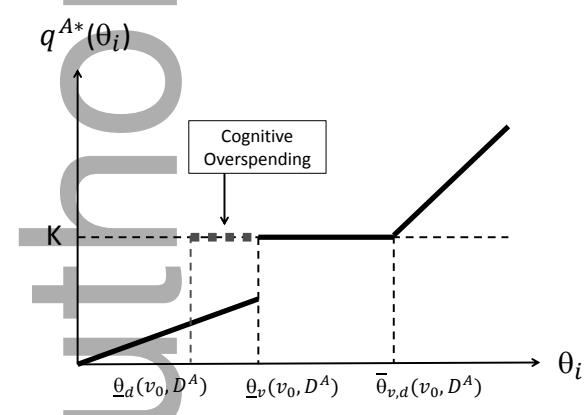

a.

Figure 8 Optimal purchase quantity under a conditional discount with a concave valuation: a. all-unit, b. fixed-
amount

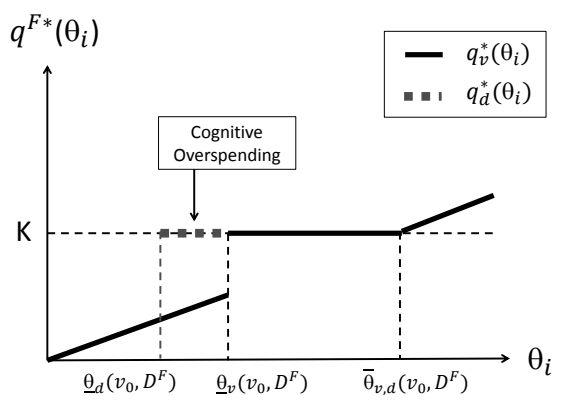

b.

We also find that there exists a region where a deal-prone consumer overspends (buys strictly more than a value-conscious consumer) under the all-unit and fixed-amount discounts, analogous

\footnotetext{
${ }^{14}$ Due to the page limit, the proof of these results and the closed-form expressions of the thresholds and the optimal purchase quantity are not included in this paper, but can be provided on request.
} 
to Corollary 1. Likewise, there exists a region $\left(\theta>\bar{\theta}_{j}\left(v_{0}, D^{A}\right)\right)$ where a consumer purchases strictly more under the all-unit discount than under the fixed-amount discount, similar to Proposition 2.

Given that the consumer's problem with concave valuation shares similar characteristics as in the base model with linear valuation, we can infer similar results for the seller's problem. First, for $D^{A}=(r, K)$ and $D^{F}=(p r K, K)$, we have that the all-unit discount weakly dominates the fixed-amount discount when consumers' valuation $\left(v_{0}\right)$ is sufficiently low, and the fixed-amount discount weakly dominates the all-unit discount otherwise. Furthermore, when all consumers have the same valuation but are different in their deal proneness, we continue to have that the all-unit and fixed-amount discounts yield the same profits for the seller.

\subsection{Endogenous Price}

Previously, we have assumed the retail price $p$ is exogenously given. Here, we extend our model to consider the situation in which the seller can optimize the retail price in addition to the discount term. Hence, the seller's problem under each discount scheme involves three decision variables: the regular price $p$, the discount rate $r$ for the all-unit discount or the discount amount $m$ for the fixed-amount discount, and the minimum purchase quantity $K$. Given large degrees of freedom in the discount terms, multiple optimal prices can exist for a given problem. However, we can show that an optimal price under the all-unit discount is either $p=s_{l}$ (all consumers are willing to pay the regular price), $p=s_{h}$ (only high-type consumers are willing to pay the regular price), or $p=\frac{s_{h} \theta_{h}+t}{\theta_{h}(1-R)}$ (no consumers are willing to pay the regular price). Similarly, an optimal price under the fixed-amount discount is either $p=s_{l}$ or $p=s_{h} \cdot{ }^{15}$ For our analysis below, we will only consider these optimal prices under the two discount schemes, without loss of optimality.

Proposition 8 summarizes key findings on the optimal price and the seller's expected profit under the all-unit and fixed-amount discounts.

Proposition 8 i) If it is optimal to price less than or equal to $s_{h}$ under the all-unit discount, then the optimal fixed-amount discount is weakly more profitable than the optimal all-unit discount. Otherwise, the optimal price under the fixed-amount discount is lower than that under the all-unit discount.

ii) In a deal-prone market with heterogeneous valuation of consumers, there exists $\bar{\Gamma}$ above which the optimal price under the all-unit and fixed-amount discounts weakly increases in the proportion of high-type consumers $(\gamma)$, and the two discount schemes result in the same consumer purchase quantities and the same seller's profit at optimality.

${ }^{15}$ See Appendix B for the proof of this result.

This article is protected by copyright. All rights reserved 
iii) In a single-valuation market with heterogeneous deal proneness of consumers, the optimal price under the all-unit and fixed-amount discounts is the same as the consumer valuation. The two discount schemes always result in the same consumer purchase quantities and the same seller's profit at optimality.

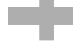

Proposition 8 shows that the overall insights, similar to the findings from Propositions 4, 6, and 7, remain the same even when the seller has the ability to set an optimal price. To further investigate the situations in which one scheme is better than the other, we numerically solve for the optimal discount terms and compare the seller's profit under 432 different scenarios (parameters as shown in Table 1, but without $p$ as a problem parameter). Our numerical result shows that the seller's decision of which discount scheme to adopt is mostly influenced by the proportion of high-type consumers, $\gamma$. More precisely, when $\gamma$ is sufficiently small or sufficiently large, the situation becomes similar to the case of $\gamma=0$ or $\gamma=1$, where the seller essentially designs the discount as if there were only one valuation type of consumers. Hence, the seller's profit under both all-unit and fixed-amount discounts is the same at optimality. On the other hand, when $\gamma$ is at a moderate level, we observe that the fixed-amount discount is more profitable than the allunit discount; as $\gamma$ increases, the all-unit discount becomes more profitable than the fixed-amount discount. This is because when a large portion of low-type consumers are present in the market, the seller needs to offer a relatively low price and set a reasonably small minimum purchase quantity for the discount to attract low-type consumers. In this case, high-type consumers can free ride more on the all-unit discount than they can under the fixed-amount discount. The situation is reversed when more consumers are high-type. Since consumers have a high willingness to pay, the seller can offer an even higher price and then discount it enough to trigger the consumers' transaction utility. Under the all-unit discount, the seller can induce high-type consumers to buy more than what they would under the fixed-amount discount with the same promotion depth and minimum purchase requirement, resulting in a greater profit to the seller.

\subsection{Menu of Discounts}

In our previous analyses, we assumed the seller can offer only one type of discount (all-unit or fixedamount) and only a single discount term $((r, K)$ for all-unit or $(m, K)$ for fixed-amount discount). Although offering only one discount on each product is prevalent in practice, certain stores do occasionally offer multiple discounts concurrently. For example, Macy's offered a $\$ 10$ off $\$ 25$ instore coupon (fixed-amount discount) while still keeping its regular offer of "15\% off 100+" (all-unit discount) for customers who sign up for its newsletter for the first time. Express offered a menu of fixed-amount discounts: $\$ 75$ off $\$ 200, \$ 40$ off $\$ 120, \$ 30$ off $\$ 100$, or $\$ 15$ off $\$ 30$. Hush Puppies 
offered a menu of all-unit discounts: buy 1 get $20 \%$ off, buy 2 get $30 \%$ off, or buy 3 take $40 \%$ off. Note, however, that even when multiple discounts are simultaneously offered to all consumers, stores typically allow each consumer to apply at most one discount on the total purchase.

When there are multiple types of consumers in the market, offering a menu of discounts can potentially improve the seller's profit over offering a single discount. To understand which menu of discounts is most profitable under which situations, we investigate three different combinations of conditional discounts: menu of fixed-amount discounts $\left\{\left(m_{i j}, K_{i j}\right)\right\}$, menu of all-unit discounts $\left\{\left(r_{i j}, K_{i j}\right)\right\}$, and menu of all-unit and fixed-amount discounts $\left\{\left(r_{i j}, K_{i j}\right),\left(m_{-(i j)}, K_{-(i j)}\right)\right\}$, for $i \in$ $\{l, h\}, j \in\{v, d\}$. Our findings indicate that in many situations, different types of menus can yield the same maximum profit to the seller. There are also many cases in which offering a single discount to multiple types of consumers is optimal (corresponding to a "pooling contract"). In general, however, we can show that whenever it is optimal to have different types of consumers purchase under different discounts, the menu of fixed-amount discounts weakly dominates the other types of menus, as stated in Proposition 9.

Proposition 9 If it is optimal to offer a menu of discounts ${ }^{16}$, then the optimal menu of fixedamount discounts weakly dominates the menu of all-unit discounts and the menu of all-unit and fixed-amount discounts. ${ }^{17}$

When different types of consumers use different discounts, it is never optimal to have any consumer purchase strictly greater than the threshold quantity (i.e., the minimum purchase quantity $K$ ) intended for her type. This is because the threshold quantity in each discount term should be set in a way that the seller's profit is maximized when the intended consumer buys the exact threshold amount. Since no consumers would buy more than their intended threshold quantities, there always exists a fixed-amount discount term that can yield the same profit as any all-unit discount term, and vice versa. However, when multiple discount terms are offered concurrently, the seller has less flexibility in designing feasible terms for a menu of all-unit discounts than fixed-amount discounts. The reason is that the seller can never offer a deeper all-unit discount with a smaller minimum purchase quantity to a lower type consumer while offering a lower discount depth with a larger minimum purchase quantity (either in the form of all-unit or fixed-amount discount) to a higher type consumer (e.g., buy 2 get $30 \%$ off, buy 4 get $25 \%$ off). Doing so would always make the lower-type discount term more attractive than the higher-type discount term to the higher type

\footnotetext{
${ }^{16}$ This refers to a situation in which offering at least two different discount terms is strictly more profitable than offering a single discount term.

${ }^{17}$ For more discussions regarding when the other types of menu can also be optimal, please see the proof of this proposition in Appendix B.
} 
consumer, hence, violating the incentive compatibility constraint. The seller can, however, offer a deeper fixed-amount discount with a smaller minimum purchase quantity to a lower type consumer (e.g., buy 2 get $\$ 6$ (30\%) off, buy 4 get $\$ 10(25 \%)$ off for a product priced at $\$ 10)$ as long as the discount amount awarded under the higher-type discount term is sufficiently larger than that under the lower-type discount term. Since the menu of fixed-amount discounts covers a larger set of feasible discount terms, it is weakly more profitable than the menu of all-unit discounts and the menu of all-unit and fixed-amount discounts.

Regarding the consumer and social welfare, the same insights discussed in section 7 continue to hold when a menu of discounts is offered. That is, an optimal menu of discounts can result in smaller or larger consumer welfare, compared to the optimal single discount. The consumer welfare under a menu of discounts is likely to be higher when it is optimal for the seller to offer multiple discount terms to attract additional types (e.g., low valuation, value-conscious) of consumers to buy. Otherwise, if the same group of consumers make a purchase under the single and the menu of discounts, the consumer welfare under the menu of discounts can be less because the seller can better screen the consumer types and extract more surplus from the consumers. The overall social welfare can be significantly improved with a menu of discounts because the mechanism is weakly more profitable to the seller than the single discount and price markdown.

\section{Conclusion}

Motivated by consumer behavior observed in retail industry, this paper discusses how price promotions influence purchase decisions of different types of consumers, and which type of promotions is most profitable to the seller under which market situations. We consider a market in which consumers can be heterogeneous in two dimensions - willingness to pay for the product and the deal proneness to a discount offer - and focus on two popular types of conditional promotions: all-unit discount and fixed-amount discount. Our study shows that deal-prone consumers may overspend when offered a conditional discount. We find, however, that it is not always optimal for the seller to induce consumer overspending. Only when a sufficiently large proportion of highly deal-prone or high-valuation consumers are present in the market can inducing overspending be profitable. Despite the fact that some consumers may overspend, the overall consumer welfare can be improved with conditional discounts, especially when transaction utility is small. Hence, conditional discounts can result in win-win situations for both consumers and retailers.

Another key finding is that, depending on the market, one conditional discount scheme can perform better than the other. We show that when consumers are not willing to pay the regular price for the product, the all-unit discount outperforms the fixed-amount discount because only the all-unit discount can induce consumers to buy strictly more than the minimum quantity required 
for the discount. On the other hand, when some consumers are already willing to pay the regular price, the fixed-amount discount is more profitable than the all-unit discount. In this case, the fixed-amount discount awards only a limited discount amount - less than that awarded under the all-unit scheme - to the consumers who otherwise would voluntarily pay the regular price. Hence, the fixed-amount discount allows the seller to maintain a greater profit margin. Based on these findings, an important implication is that an all-unit discount should be adopted to stimulate sales of a high-price-tag product or a newly launched item, whereas a fixed-amount discount is more effective as a frequent promotion of a low-price-tag or established brand-name product. Our key results are robust to changes in modeling assumptions, suggesting that the insights from this paper apply to a broad range of realistic retailing situations.

Operationally, the focus of our paper is rather different from that of existing literature on discount management. Previous studies on price markdowns, for instance, mostly focused on when to offer how much of a discount given the remaining inventory and selling horizon. The intertemporal pricing literature also studied the timing and pattern of discounts, but often considered the strategic behavior of consumers. Our paper took a different focus by investigating how the structure of price promotions (terms of discounts) affects purchase quantity of different types of consumers in a single-period setting. Hence, constraints on product inventory, selling horizon, and consumer strategic behavior are not explicitly incorporated in our model. We conjecture, however, that conditional discounts can be effectively implemented over multiple periods as well, but if inventory is limited and consumers are strategic, the optimal discount terms might require just a small minimum purchase quantity and offer a moderate discount in some periods. By considering a single-period setting, we note that our findings are more applicable to short shelf life products (e.g., food, fashion goods, seasonal items), whose excess inventory close to the end of the selling horizon can be effectively sold through a conditional discount. For long shelf life products in a multiple-period setting, the profitability of a conditional promotion may be reduced in a later period due to consumer stockpiling during the earlier promotional periods, and the less sensitivity (in the form of a smaller transaction utility or a higher threshold) of deal-prone consumers towards a deal when offered in multiple periods. A few other aspects of price promotions and consumer psychology can serve as interesting future research directions. One area involves post-promotion effects, such as sticker shock after the promotional period ends. Such an effect may be more or less intense under different discount schemes, and may pose a limitation on the discount depth that should be offered. Another area is the effect of framing: how a promotion is framed (e.g., dollars off, percent off, Buy-X-Get-Y-Free, Buy-X-for-Y) and how it is awarded (e.g., coupons, straight off the shelf). Taking consumer psychological responses to different forms of promotions into account,

\section{This article is protected by copyright. All rights reserved}


the seller's joint decision on the discount term and its vehicle can be complicated yet meaningful to study.

\section{Acknowledgments}

The authors are grateful for the constructive comments from the editor and the referees which helped improve the paper significantly throughout the review process.

\section{References}

Amornpetchkul, T. 2017. Threshold discounts comparison: All-unit or incremental? J Revenue Pricing Manag 16(3) $265-294$

Bell, D. R., J. Chiang, V. Padmanabhan. 1999. The decomposition of promotional response: An empirical generalization. Marketing Sci. 18(4) 504-526.

Besbes, O., I. Lobel. 2015. Intertemporal price discrimination: Structure and computation of optimal policies. Management Sci. 61(1) 92-110.

Blattberg, R. C., G. D. Eppen, J. Lieberman. 1981. A theoretical and empirical evaluation of price deals for consumer nondurables. J. Marketing 45(1) 116-129.

Borrell Associates, Inc. 2010. Proximity-based marketing: Mobile devices untether advertising from media.

Chen, S. S., K. B. Monroe, Y. Lou. 1998. The effects of framing price promotion messages on consumers' perceptions and purehase intentions. J. Retailing 74(3) 353-372.

Chuang, J. C., M. A. Sirbu. 1999. Optimal bundling strategy for digital information goods: network delivery of articles and subscriptions. Inf. Econ. Policy 11 147-176.

Corbett, C. J., X. de Groote. 2000. A supplier's optimal quantity discount policy under asymmetric information. Management Sci. 46(3) 444-450.

Dada, M., K. N. Srikanth. 1987. Pricing policies for quantity discounts. Management Sci. 33(10) 1247-1252.

DelVecchio, D. 2005. Deal-prone consumers' response to promotion: The effects of relative and absolute promotion value. Psychol. Market. 22(5) 373-391.

DelVecchio, D., H. S. Krishnan, D. C. Smith. 2007. Cents or percent? the effects of promotion framing on price expectations and choice. J. Marketing 71(3) 158-170.

Fontinelle, A. Aug. 17, 2011. 6 sneaky ways coupons make you spend more. Investopedia .

Foubert, B., E. Gijsbrechts. 2007. Shopper response to bundle promotions for packaged goods. J. Marketing Res. 44(4) 647-662.

Gendall, P., J. Hoek, T. Pope, K. Young. 2006. Message framing effects on price discounting. J. of Product $\mathcal{E} 3$ Brand Management 15(7) 458-465.

Greenleaf, E. A. 1995. The impact of reference price effects on the profitability of price promotions. Marketing Sci. 14(1) 82-104.

Gupta, D., A. V. Hill, T. Bouzdine-Chameeva. 2006. A pricing model for clearing end-of-season retail inventory. Eur. J. Oper. Res. 170(2) 518-540.

Hackleman, E. C., J. M. Duker. 1980. Deal proneness and heavy usage: Merging two market segmentation criteria. J. Acad. Market. Sci. 8(4) 332-344.

Hanson, W., R. K. Martin. 1990. Optimal bundle pricing. Management Sci. 36(2) 155-174.

Hardesty, D. M., W. O. Bearden. 2003. Consumer evaluations of different promotion types and price presentations: the moderating role of promotional benefit level. J. Retailing $\mathbf{7 9}$ (1) 17-25.

\section{This article is protected by copyright. All rights reserved}


Heath, T. B., S. Chatterjee, K. R. France. 1995. Mental accounting and changes in price: The frame dependence of reference dependence. J. Consum. Res. 22(1) 90-97.

Herrmann, A., F. Huber, R. H. Coulter. 1997. Product and service bundling decisions and their effects on purchase intention. Pricing Strategy and Practice 5(3) 99-107.

Jeuland, A. P., C. Narasimhan. 1985. Dealing-temporary price cuts-by seller as a buyer discrimination mechanism. J. Bus. 58(3) 295-308.

Klaft, H. Sep. 3, 2011. Coupon fever: Using deals to save on groceries a way of life for local woman. Jackson Citizen Patriot.

Krishnamurthi, L., T. Mazumdar, S. P. Raj. 1992. Asymmetric response to price in consumer brand choice and purchase quantity decisions. J. Consum. Res. 19(3) 387-400.

Kukar-Kinney,-M., N. M. Ridgway, K. B. Monroe. 2012. The role of price in the behavior and purchase decisions of compulsive buyers. J. Retailing 88(1) 63-71.

Laroche, M., F. Pons, N. Zgolli, M. Cervellon, C. Kim. 2003. A model of consumer response to two retail sales promotion techniques. J. Bus. Res. 56 513-522.

Laroche, M., F. Pons, N. Zgolli, C. Kim. 2001. Consumers use of price promotions: a model and its potential moderators. J. Retailing Consum. Services 8 251-260.

Lazear, E. P. 1986. Retail pricing and clearance sales. Am. Econ. Rev. 76(1) 14-32.

Lee, L., D. Ariely. 2006. Shopping goals, goal concreteness, and conditional promotions. J. Consum. Res. 33(1) $60-70$.

Lichtenstein, D. R., S. Burton, R. G. Netemeyer. 1997. An examination of deal proneness across sales promotion types: A consumer segmentation perspective. J. Retailing 73(2) 283-297.

Lichtenstein, D. R., R. G. Netemeyer, S. Burton. 1990. Distinguishing coupon proneness from value consciousness: An acquisition-transaction utility theory perspective. J. Marketing 54(3) 54-67.

Mazumdar, T., S. P. Raj, I. Sinha. 2005. Reference price research: Review and propositions. J. Marketing 69(4) $84-102$.

Monahan, J. P. 1984. A quantity discount pricing model to increase vendor profits. Management Sci. 30(6) $720-726$.

NCH Marketing Services, Inc. 2011. Coupon facts report.

Popescu, I., Y.Wu. 2007. Dynamic pricing strategies with reference effects. Oper. Res. 55(3) 413-429.

Schindler, R. M. 1992. A coupon is more than a low price: Evidence from a shopping-simulation study. Psychol. Market. 9(6) 431-451.

Schindler, R. M. 1998. Consequences of perceiving oneself as responsible for obtaining a discount: Evidence for smart-shopper feelings. J. Consum. Psychol. 7(4) 371-392.

Schmalensee, R. 1984. Gaussian demand and commodity bundling. J. Bus. 57(1) S211-S230.

Sherman, L. Feb. 5, 2009. Eight reasons why we overspend. Forbes .

Singer, A. E., S. Lysonski, M. Singer, D. Hayes. 1991. Ethical myopia: The case of framing by framing. J. Bus. Ethics 10(1) 29-36.

Smith, S. A., D. D. Achabal. 1998. Clearance pricing and inventory policies for retail chains. Management Sci. 44(3) $285-300$.

$\mathrm{Su}$, X. 2007. Intertemporal pricing with strategic customer behavior. Management Sci. 53(5) 726-741.

Thaler, R. 1985. Mental accounting and consumer choice. Marketing Sci. 4(3) 199-214.

Thaler, R. H. 1999. Mental accounting matters. J. Behav. Decis. Making 12(3) 183-206.

Tsai, D. 2007. Cash rewards effect on unplanned buying behaviors-watch your wallet carefully! Consumer Interests Annual, Nbr. 53 .

\section{This article is protected by copyright. All rights reserved}


Tuttle, B. Jul. 23, 2010. Bound to buy: The 10 types of consumers who inevitably overspend. TIME .

Varian, H. R. 1980. A model of sales. Am. Econ. Rev. 70(4) 651-659.

Venkatesh, R., V. Mahajan. 1993. A probabilistic approach to pricing a bundle of products or services. J. Marketing Res. 30(4) 494-508.

Wansink, B., R. J. Kent, S. J. Hoch. 1998. An anchoring and adjustment model of purchase quantity decisions. J. Marketing Res. 35(1) 71-81.

Weng, Z. K. 1995. Modeling quantity discounts under general price-sensitive demand functions: Optimal policies and relationships. Eur. J. Oper. Res. 86 300-314.

Wilcox, J. B., R. D. Howell, P. Kuzdrall, R. Britney. 1987. Price quantity discounts: Some implications for buyers and sellers. J. Marketing 51(3) 60-70.

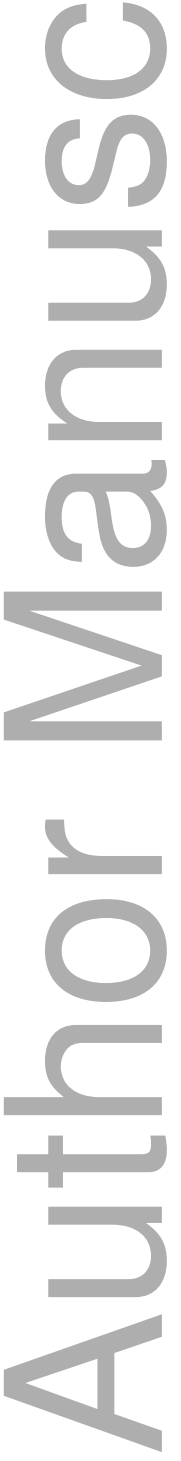




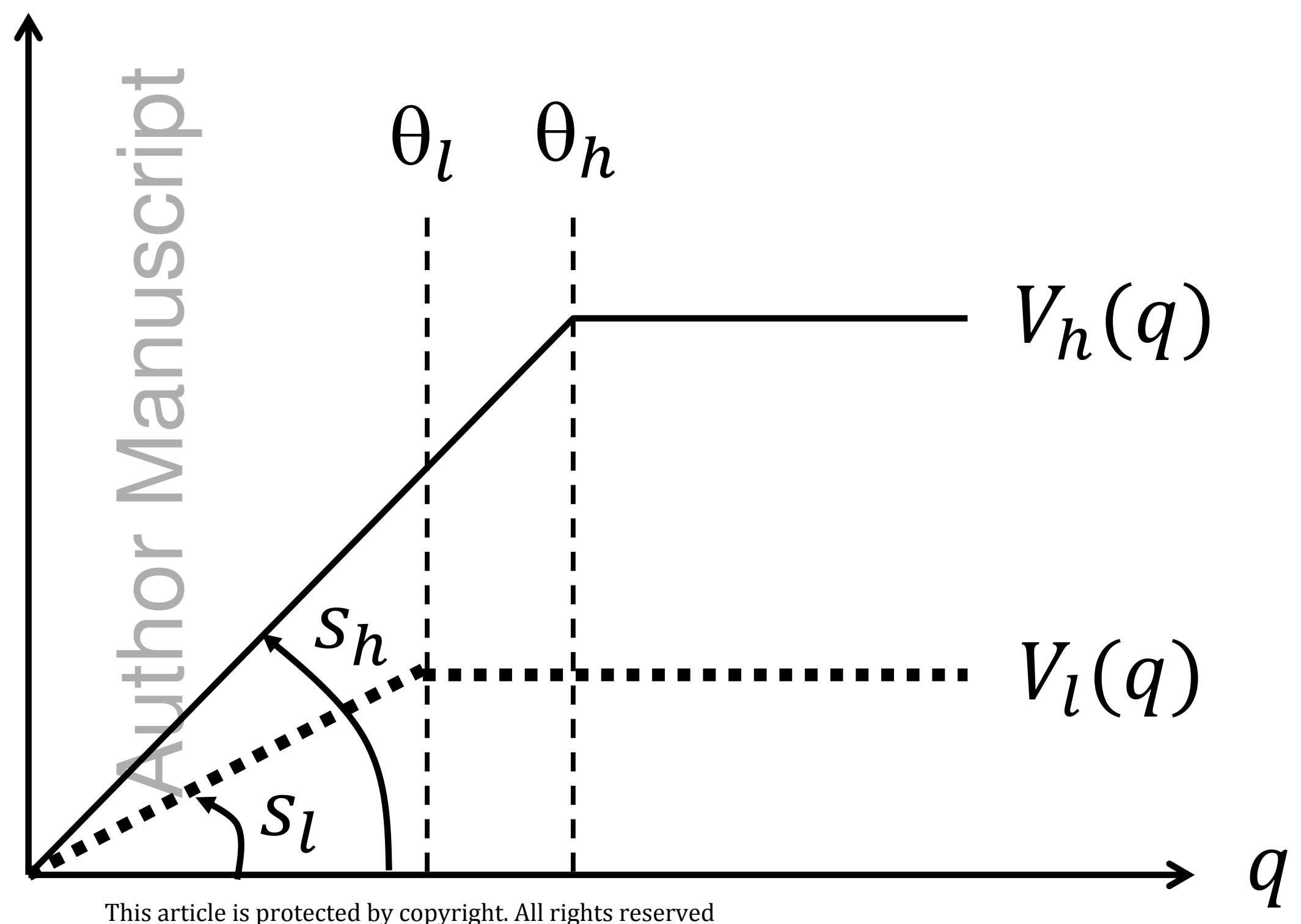

This article is protected by copyright. All rights reserved 


\section{Value-Conscious}

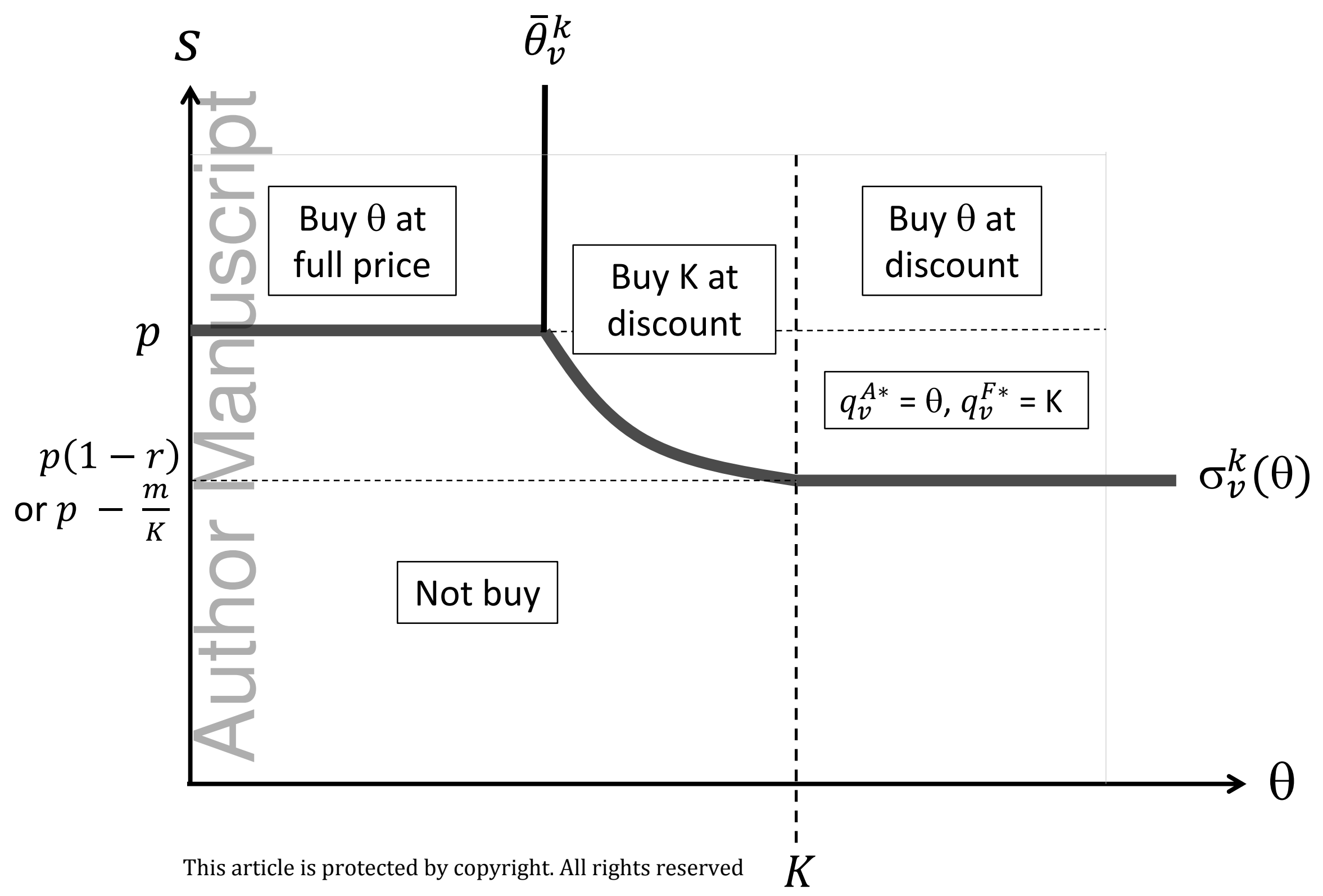




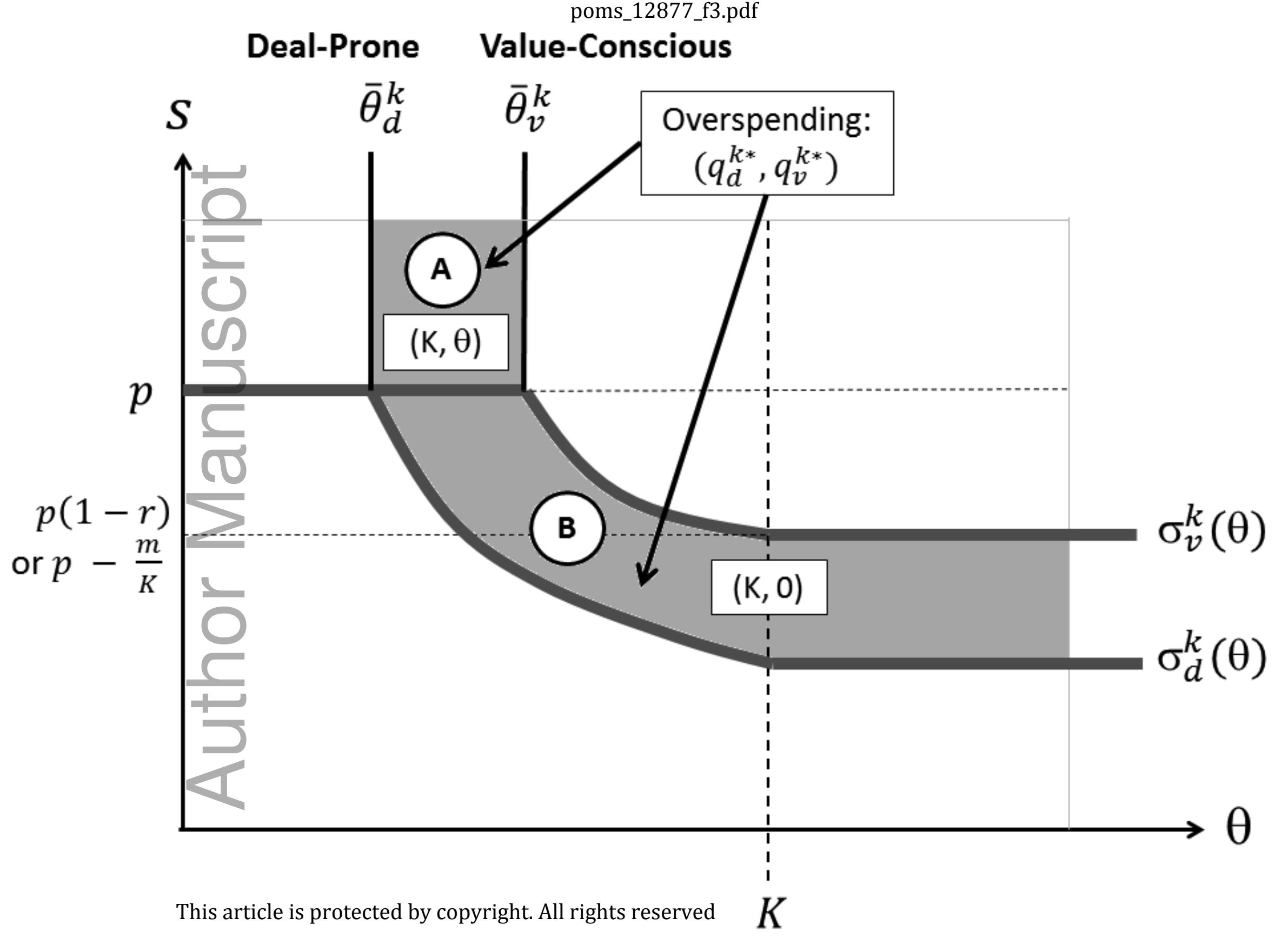




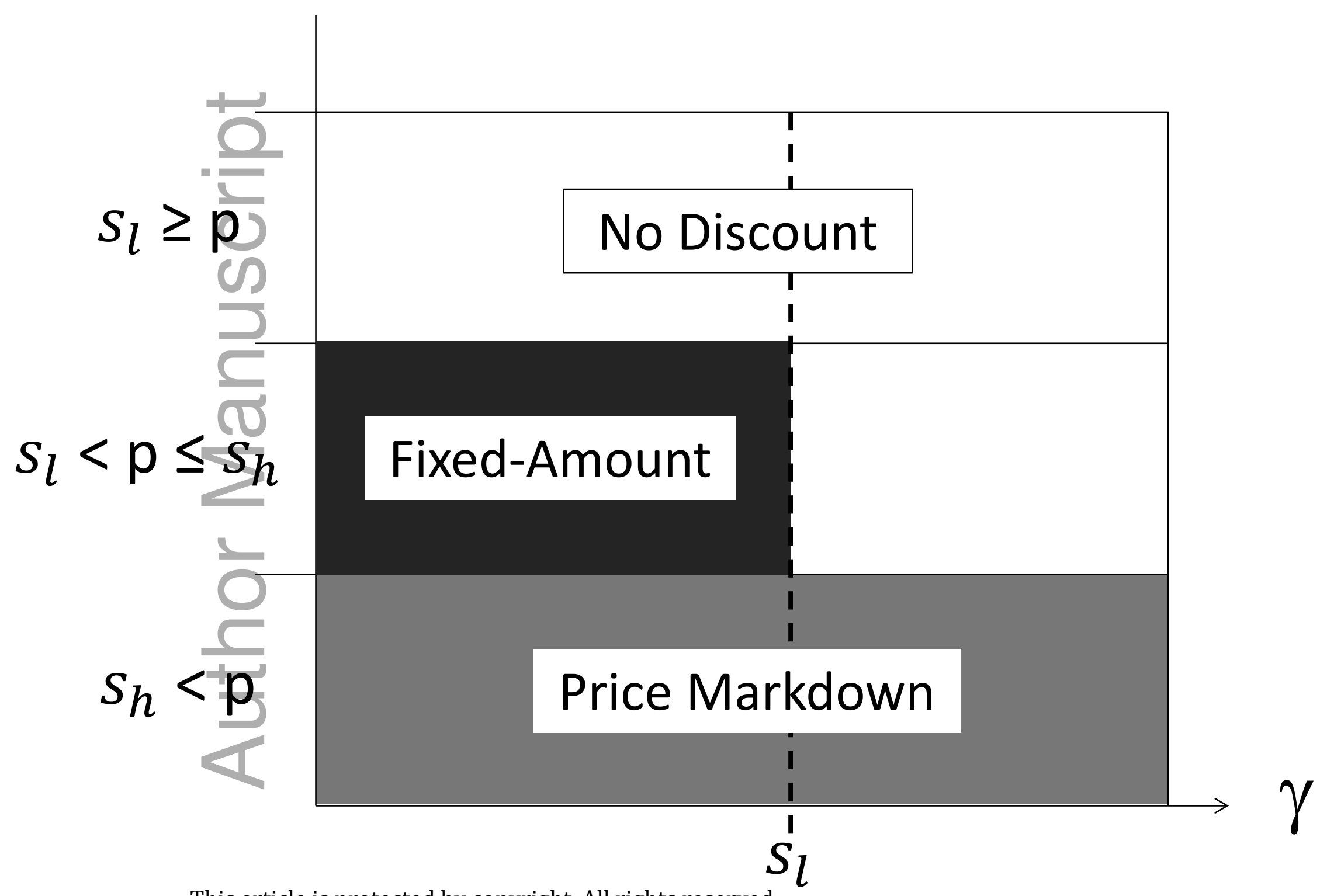

This article is protected by copyright. All rights reserved

$p$ 


\section{Fixed-Amount}

$s_{l}<\mathrm{p} \leq s_{h}$

\section{Price Markdown}




\section{Fixed-Amount}

$s_{l}<\mathrm{p} \leq s_{h}$

\section{All-Unit}


poms_12877_f5.pdf

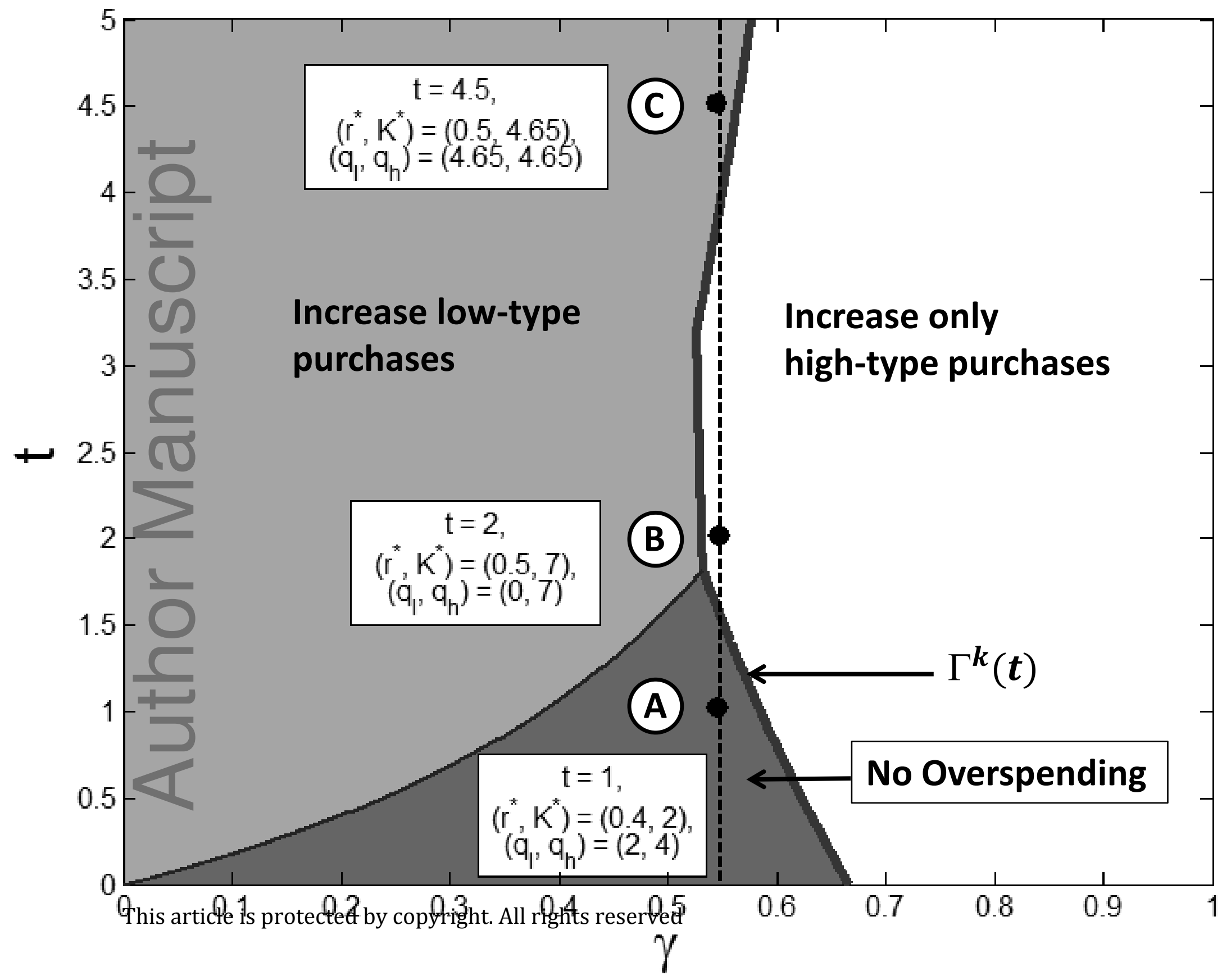


poms_12877_f6a.pdf

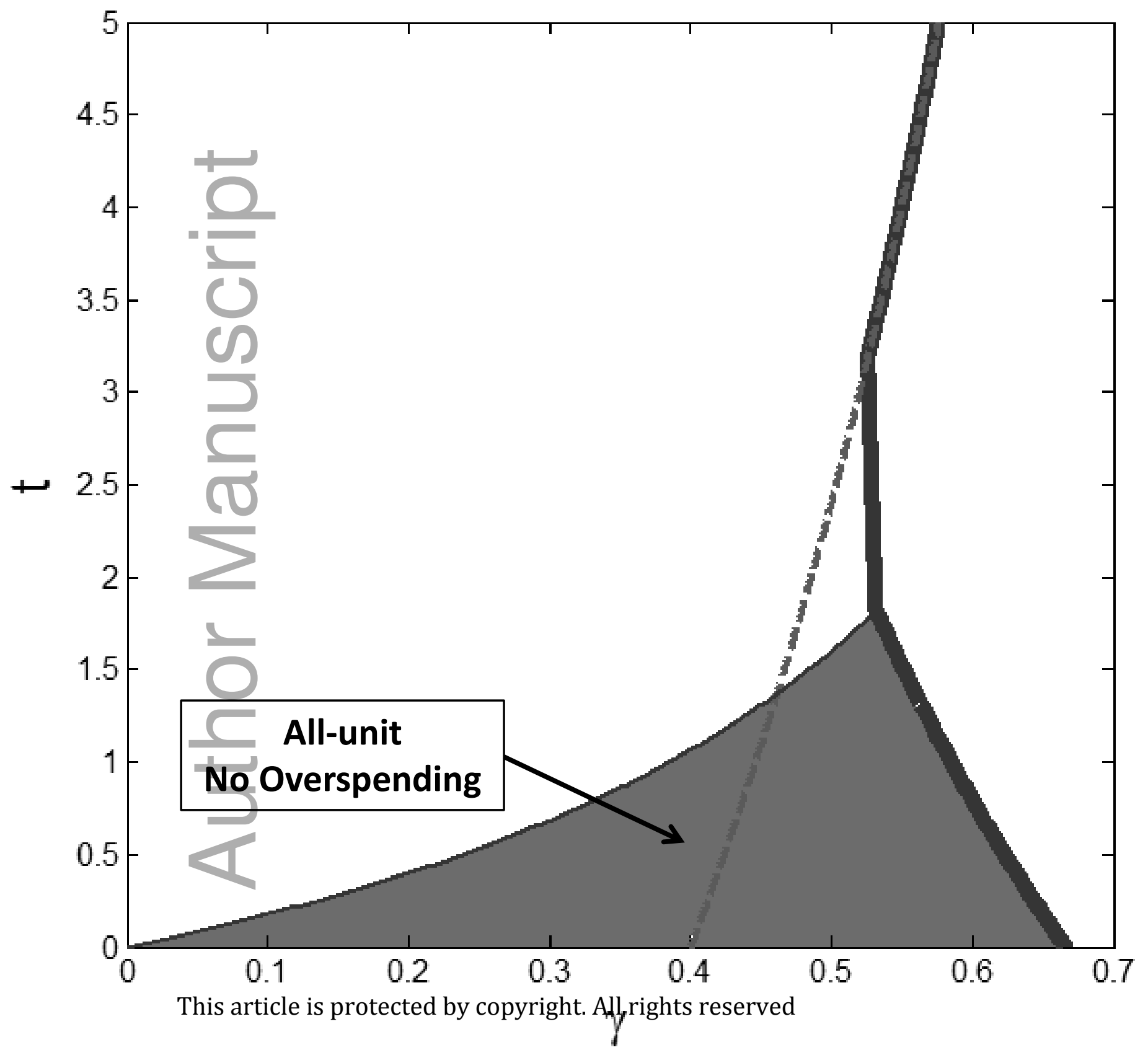


poms_12877_f6b.pdf

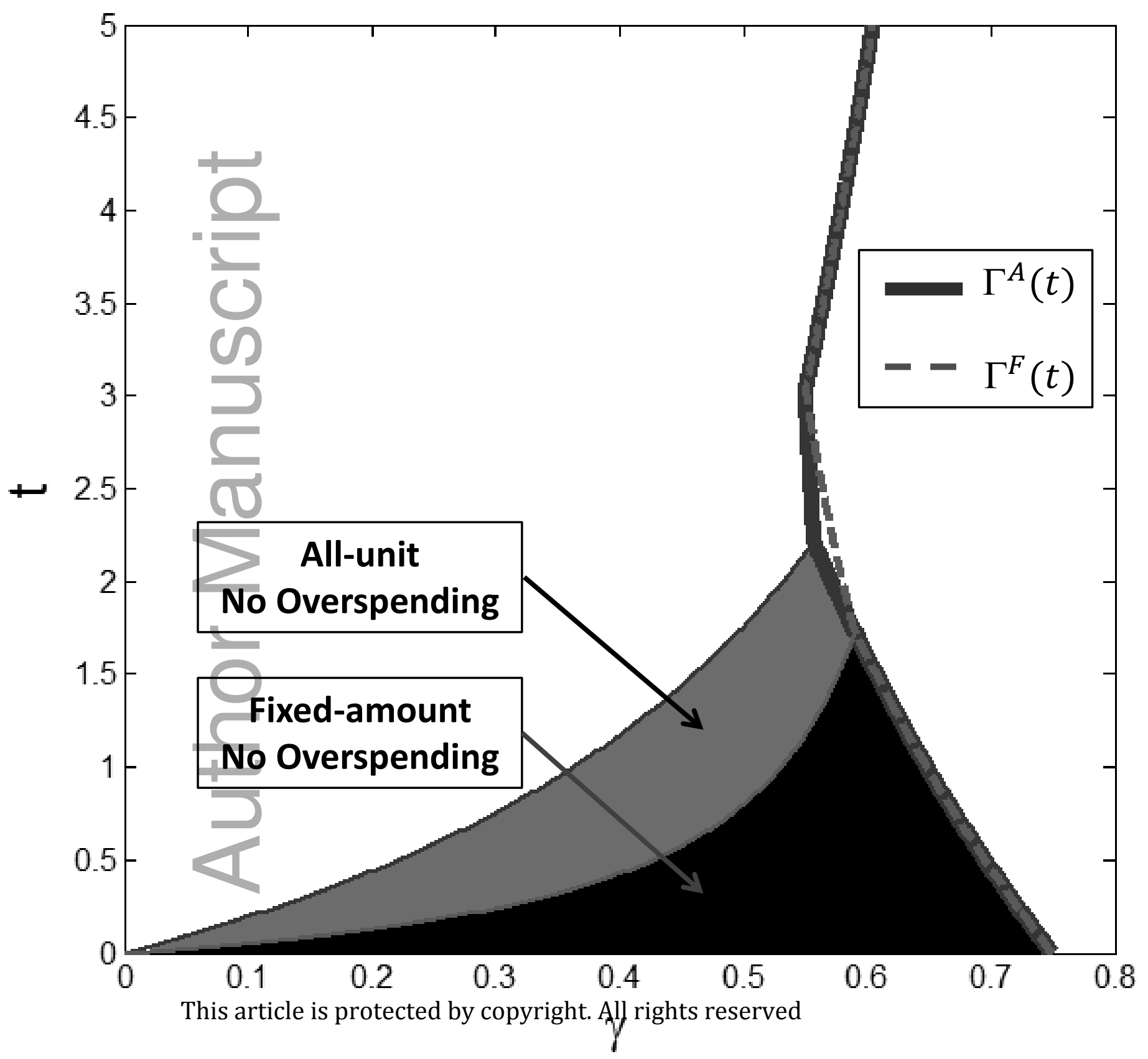




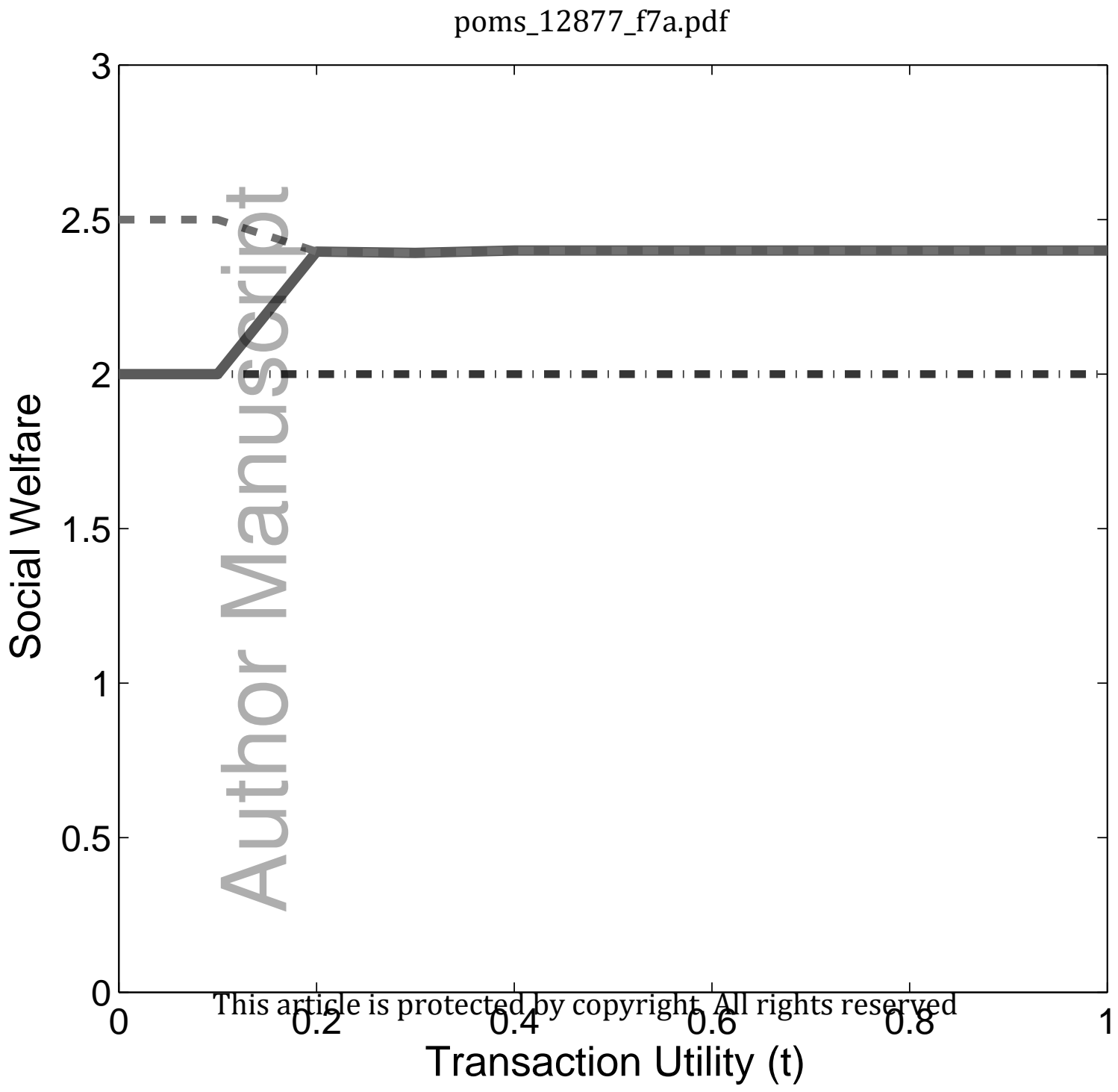


poms_12877_f7b.pdf

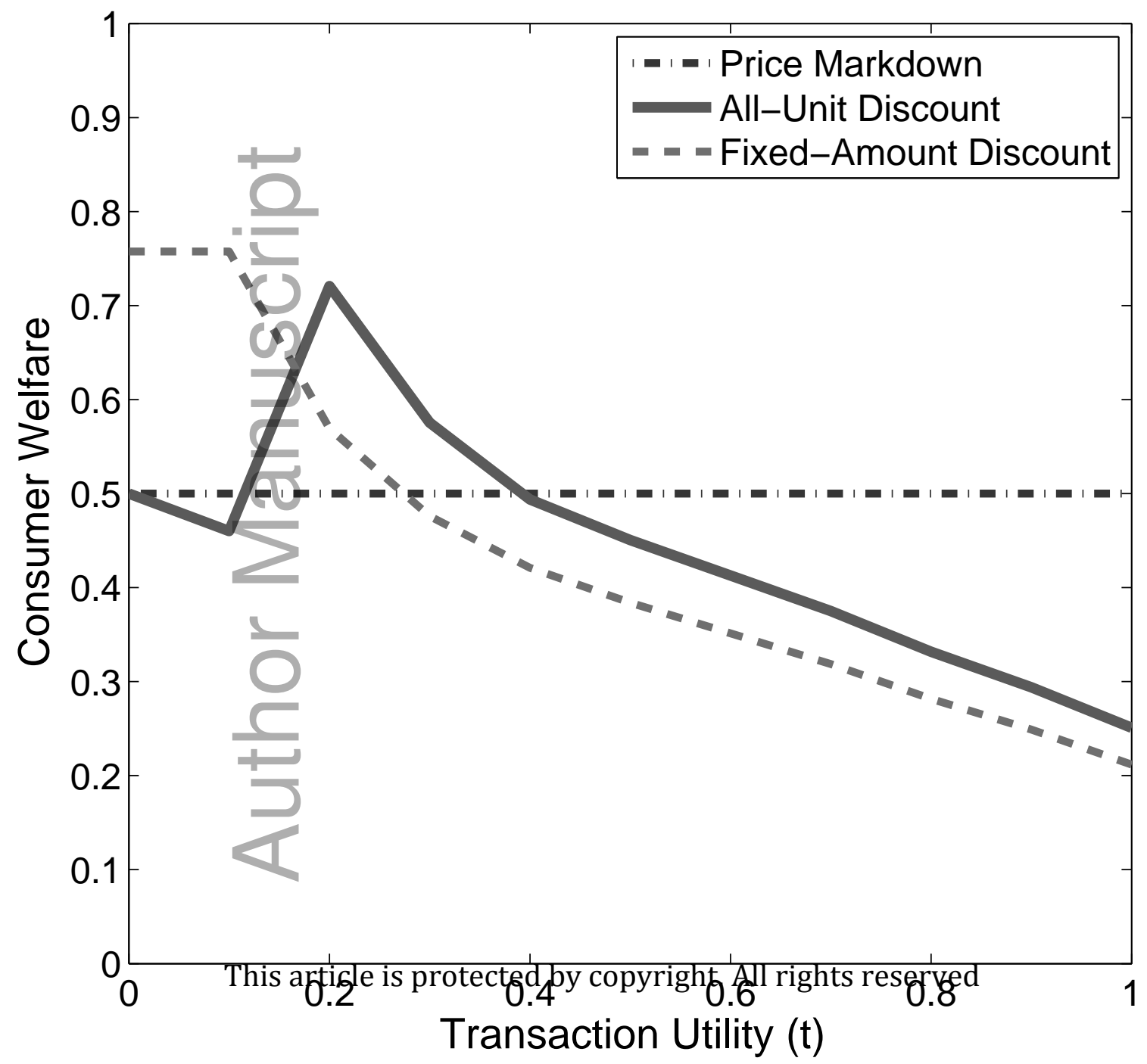


$q^{A *}\left(\theta_{i}\right)$

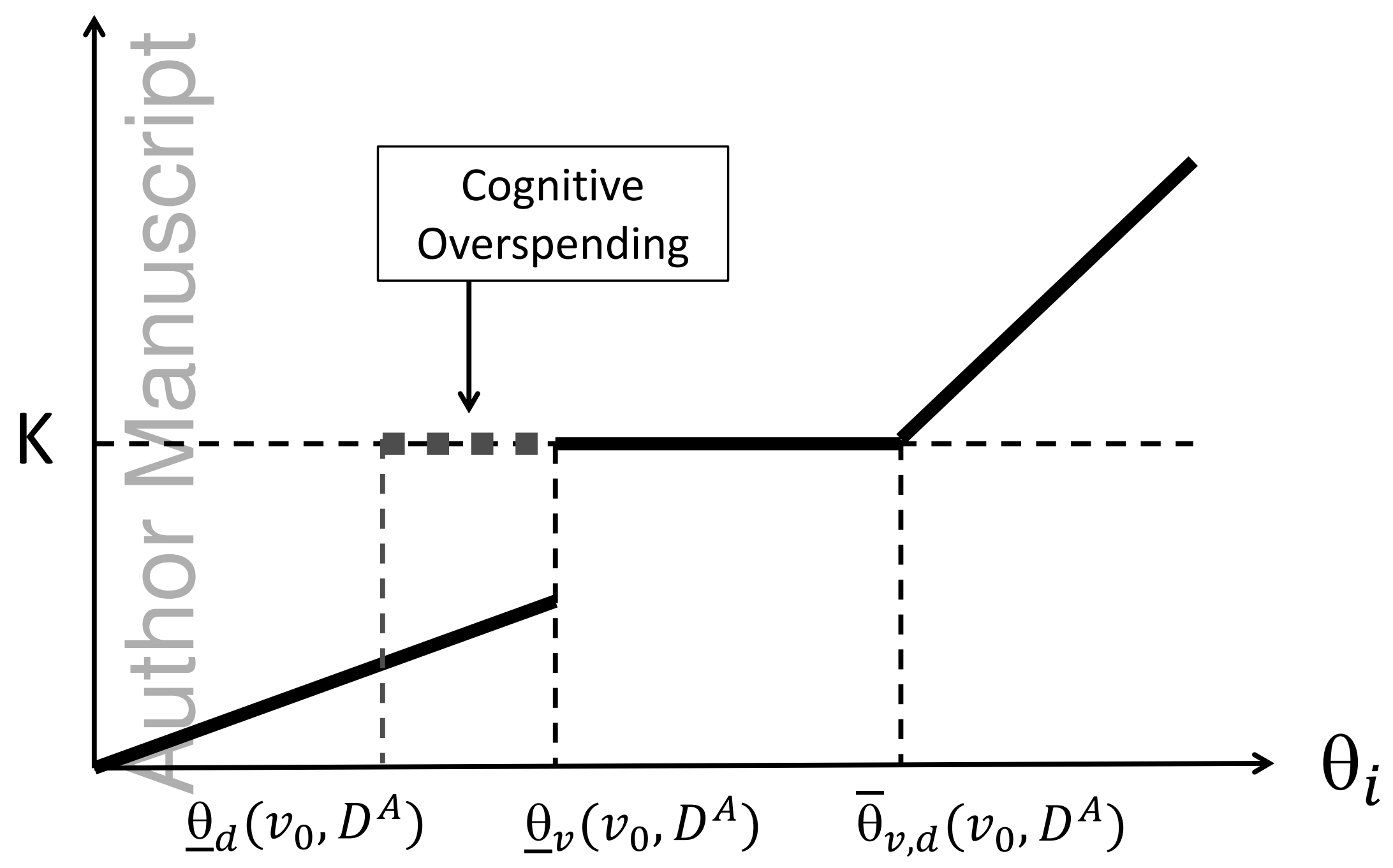

This article is protected by copyright. All rights reserved 
$q^{F *}\left(\theta_{i}\right)$

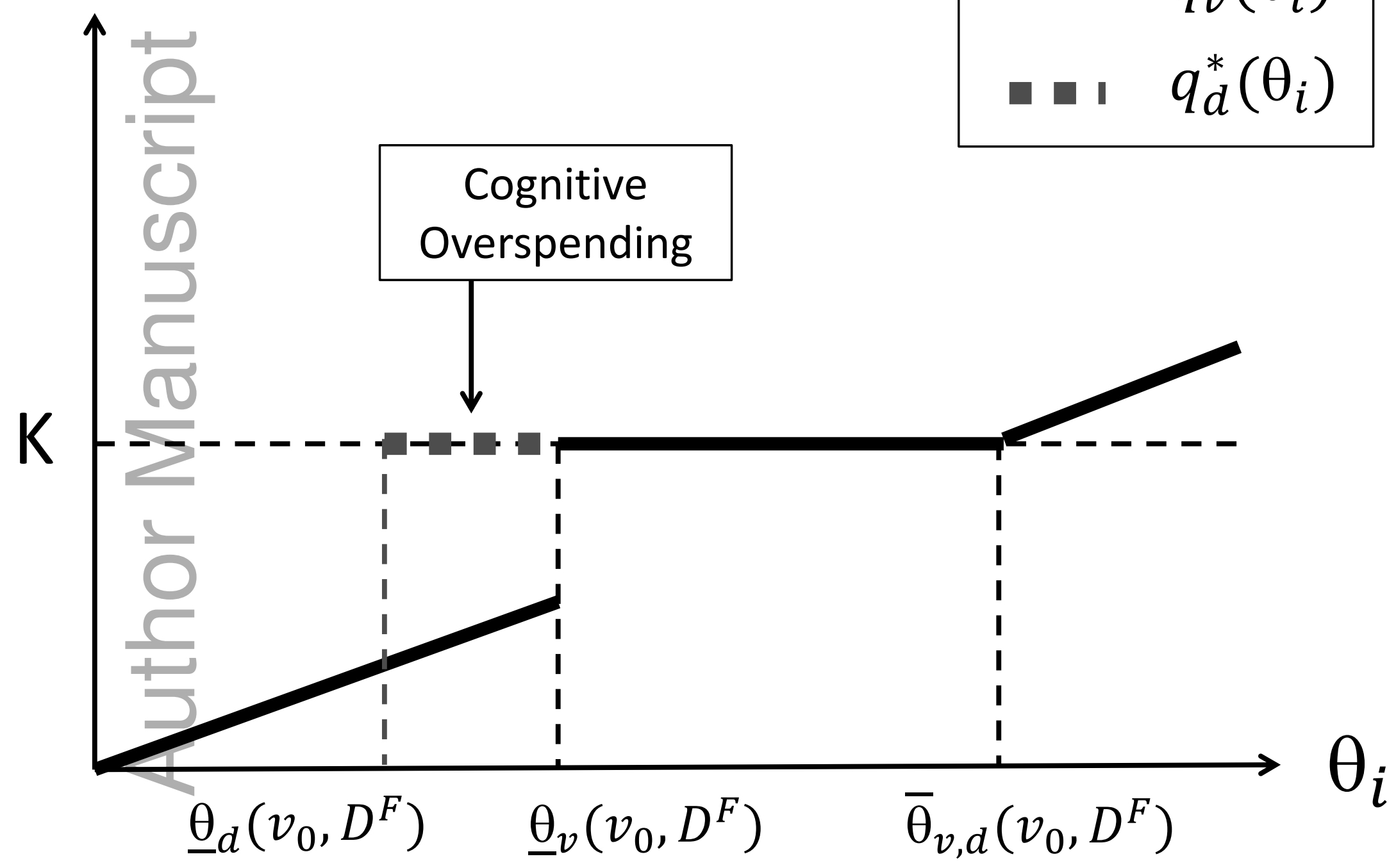

This article is protected by copyright. All rights reserved 